\title{
De novo emergence of a remdesivir resistance mutation during treatment of persistent SARS-CoV-2 infection in an immunocompromised patient: A case report
}

Shiv Gandhi*1†, Jonathan Klein*2, Alexander Robertson ${ }^{3 *}$, Mario A. Peña-Hernández*2, Michelle J Lin ${ }^{4}$, Pavitra Roychoudhury ${ }^{4}$, Peiwen Lu², John Fournier ${ }^{1}$, David Ferguson ${ }^{5}$, Shah A. Mohamed Bakhash ${ }^{4}$, M. Catherine Muenker ${ }^{3}$, Ariktha Srivathsan ${ }^{3}$, Elsio A. Wunder Jr ${ }^{3}$, Nicholas Kerantzas ${ }^{6}$, Wenshuai Wang ${ }^{7}$, Brett Lindenbach ${ }^{8}$, Anna Pyle ${ }^{7,9,11}$, Craig B. Wilen ${ }^{2,6}$, Onyema Ogbuagu ${ }^{1}$, Alexander L. Greninger ${ }^{4,10}$, Akiko Iwasaki ${ }^{2,3,7,11}$, Wade L. Schulz ${ }^{5,6}$, and Albert I. Ko $\mathrm{Ko}^{1,3 \dagger}$

${ }^{1}$ Department of Medicine, Section of Infectious Diseases, Yale University School of Medicine, New Haven, CT, USA

${ }^{2}$ Department of Immunobiology, Yale University School of Medicine, New Haven, CT, USA

${ }^{3}$ Department of Epidemiology of Microbial Diseases, Yale School of Public Health, New Haven, CT, USA

${ }^{4}$ Department of Laboratory Medicine, University of Washington School of Medicine, Seattle, Washington, USA

${ }^{5}$ Center for Outcomes Research and Evaluation, Yale New Haven Hospital, New Haven, CT, USA

${ }^{6}$ Department of Laboratory Medicine, Yale School of Medicine, New Haven, CT, USA

${ }^{7}$ Department of Molecular, Cellular and Developmental Biology, Yale University, New Haven, CT, USA

${ }^{8}$ Department of Microbial Pathogenesis, Yale School of Medicine, New Haven, CT, USA

${ }^{9}$ Department of Chemistry, Yale University, New Haven, CT, USA

${ }^{10}$ Vaccine and Infectious Disease Division, Fred Hutchinson Cancer Research Center, Seattle, Washington, USA

${ }^{11}$ Howard Hughes Medical Institute, Chevy Chase, MD, USA.

*These authors contributed equally

Corresponding Authors ${ }^{\dagger}$ : S.G. (shiv.gandhi@yale.edu), A.I.K. (albert.ko@yale.edu) 


\begin{abstract}
SARS-CoV-2 remdesivir resistance mutations have been generated in vitro but have not been reported in patients receiving treatment with the antiviral agent. We present a case of an immunocompromised patient with acquired B-cell deficiency who developed an indolent, protracted course of SARS-CoV-2 infection. Remdesivir therapy alleviated symptoms and produced a transient virologic response, but her course was complicated by recrudescence of high-grade viral shedding. Whole genome sequencing identified a mutation, E802D, in the nsp12 RNA-dependent RNA polymerase, which was not present in pre-treatment specimens. In vitro experiments demonstrated that the mutation conferred a $\sim 6$-fold increase in remdesivir $\mathrm{IC}_{50}$ but resulted in a fitness cost in the absence of remdesivir. Sustained clinical and virologic response was achieved after treatment with casirivimab-imdevimab. Although the fitness cost observed in vitro may limit the risk posed by E802D, this case illustrates the importance of monitoring for remdesivir resistance and the potential benefit of combinatorial therapies in immunocompromised patients with SARS-CoV-2 infection.
\end{abstract}

\title{
Text
}

Remdesivir (RDV), an adenosine nucleoside analog that interferes with the SARS-CoV-2 RNA polymerase, nsp12, when converted to its active form ${ }^{1}$, has been widely used in the treatment of patients hospitalized with COVID-19. In vitro selection experiments have generated mutations at residue 802 of nps12, which confer resistance to $\mathrm{RDV}^{2}$. These mutations have been detected in genome sequences deposited in GISAID ${ }^{2}$, but their emergence has not been demonstrated in patients receiving RDV therapy. Selection for RDV resistance is a specific concern for immunocompromised patients who may receive multiple courses of the antiviral agent for persistent SARS-CoV-2 infection ${ }^{3-5}$. Here, we report a case of an immunocompromised patient 
with an indolent, protracted course of SARS-CoV-2 infection from whom a RDV resistance mutation, E802D, was identified during recrudescence of viral shedding following treatment with the antiviral agent.

A woman in her 70s with Stage IV Non-Hodgkin's lymphoma (NHL) had completed a course of rituximab and bendamustine in March 2019, which was complicated by lymphocytopenia and hypogammaglobinemia. The NHL was in remission when she developed a SARS-CoV-2 infection in May 2020, which presented as the acute onset of fever, anosmia, cough and rhinorrhea (Figure 1a) and was confirmed by reverse transcriptase-polymerase chain reaction (RT-PCR) on day 0 (Figure 1b). The patient was hospitalized twice in the following two months for persistent fever and new onset neutropenia and anemia (Figure 1c), during which she had low SARS-CoV-2 RT-PCR cycle threshold $(\mathrm{Ct})$ values from nasopharyngeal specimens $(\mathrm{Ct} 20.5$ and 17.1 on days 17 and 36, respectively, Figure 1b), undetectable serum anti-SARS-CoV-2 IgG antibody (Abbott), and elevated serum inflammatory markers (Figure 1c). Chest computed tomography (CT) revealed bilateral ground glass opacities (day 38, Figure 1d), but she did not experience dyspnea, hypoxemia or recurrence of respiratory symptoms during her hospitalizations and subsequent course of illness. The workup for other sources of fever, which included a bone marrow biopsy, was unrevealing. CD19 ${ }^{+}$B-cells were not identified in the bone marrow biopsy or by flow-cytometry of peripheral blood mononuclear cells (PBMC). The patient was initiated on treatment with filgrastim 1-2 times per week and monthly intravenous immunoglobulin (IVIG) to manage her neutropenia and hypogammaglobulinemia, respectively, and both were continued after hospital discharge on day 51.

The patient continued to have daily fevers, except for a 30-day period of defervescence (days 103-132), refractory neutropenia, anemia, and positive RT-PCR test results with Ct values $<25$ 
when she was hospitalized at our institution on day 145. Her chest CT on day 140 was notable for increased opacities compared with prior examinations (Figure 1d). The patient initiated a 10day course of RDV (days 148-157), which precipitated a resolution of her fever (day 149, Figure 1a), normalization of CRP (day 156, Figure 1c) and improvement in the opacities on chest CT (day 162, Figure 1d). An initial virologic response to therapy was observed, with an increase in RT-PCR Ct values and decreasing numbers of plaque forming units (PFU) in viral cultures and lower proportions of SARS-CoV-2 subgenomic RNA (sgRNA), measured in amplicon sequencing data, in her respiratory tract specimens by day 152 (Figure 2a).

However, a recrudescence of viral shedding occurred during and after RDV therapy, as evidenced by decreasing RT-PCR Ct values which reached 18 on day 160 and increasing PFU and sgRNA in respiratory tract specimens on day 156 (Figure $2 \mathrm{a}$ ). The patient received an $8 \mathrm{~g}$ infusion of casirivimab-imdevimab ${ }^{6,7}$ on day 163 after expanded access for the use of the monoclonal antibody $(\mathrm{mAb})$ therapy was approved. A rapid and sustained virologic response was observed with undetectable cultured virus, low sgRNA and negative NP RNA in specimens by days 164, 166 and 217, respectively. The patient's anosmia resolved roughly 17 days after administration of casirivimab-imdevimab (day 180. Figure 1a). During the following five-month period (days 160-292), the patient did not have recurrence of COVID-19 related symptoms and had a chest CT which showed minimal opacities (day 170, Figure 1d), and had high anti-SARSCoV-2 S1 protein IgG titers (Figure 2a). Peripheral blood neutrophil counts, hemoglobin levels and serum inflammatory markers normalized during convalescence (Figure 1c).

To identify SARS-CoV-2 mutations that arose during the course of illness, we longitudinally sampled multiple sources of the patient's tissues and secretions (Supplemental Table 1) and performed WGS on an Illumina NextSeq platform using the Swift SARS-CoV-2 multiplex 
amplicon sequencing panel $^{8}$. Viral N1 or N2 RNA was detected in 19 of 21 nasopharyngeal, 10 of 10 saliva, 10 of 10 stool and 0 of 10 whole blood specimens. Among the 39 samples with detectable N1 or N2 RNA, we assembled 27 whole SARS-CoV-2 genomes from nasopharyngeal (12), saliva (9) and stool (6) specimens. One of the nasopharyngeal specimens was obtained from the initial phase of illness (day 36, Figure 2a). Phylogenetic analysis found that sequenced genomes belonged to a single lineage (Pango B1) within Nextstrain clade 20C (Figure S1), indicating that viral genomes identified during the course of illness were derived from intra-host diversification following infection with a single strain.

Analysis of assembled viral genomes identified a mutation, E802D, in nsp12, whose detection in patient specimens was temporally associated with RDV therapy (Figure 2b). E802D was not identified at an allele frequency above $1 \%$ in either the specimen obtained during the initial phase of illness (day 36) or in specimens collected during the first 5 days (days 148-152) of RDV therapy. The mutation was first detected 7 days after initiation of RDV therapy (day 155) and accounted for $23 \%$ and $96 \%$ of the allele frequency in nasopharyngeal and saliva specimens, respectively, by day 160 . The E802 residue of nsp12 resides in the palm sub-domain which contains a portion of the residues that comprise the active site of the SARS-CoV-2 RNA polymerase ${ }^{1,2,9}$. The E802 residue participates in an electrostatic network with D804 and K807 which stabilizes the loop involved with binding to the nascent RNA (Figure 2c, S2a). E802D has been identified in an in vitro RDV resistance selection experiment and was found to confer a $\sim 2.5$-fold increase in $\mathrm{IC}_{50}$ to the $\mathrm{drug}^{2}$. Together, the temporality of E802D emergence in the patient, its location in nsp12 and the in vitro identification of the same mutation with a RDV resistance phenotype support the plausibility that that RDV treatment of the patient selected for 
variants with the E802D mutation, which in turn contributed to the observed rebound viral shedding.

To validate the resistance phenotype of E802D, we engineered this mutation and an E802A mutation, which had been also shown to confer RDV resistance ${ }^{2}$, into an infectious molecular clone of SARS-CoV-2/WA01 (icSARS-CoV-2-mNG), which expresses the mNeon Green reporter and is ORF7a depleted ${ }^{10}$. Replication kinetics of the E802D and E802A mutants in Vero-E6 cells revealed decreased viral replication relative to parental icSARS-CoV-2-mNG (Figure 2d), suggesting that these mutations may impart a fitness cost. In the presence of high concentrations of RDV $(5 \mu \mathrm{M})$, the E802D mutant replicated to higher titers than the parental virus (Figure S2b), confirming that this mutation confers resistance to RDV. RDV dose-response curves demonstrated that E802D and E802A mutants had significant increases in $\mathrm{IC}_{50}$ values (4.2 $\mu \mathrm{M}$ and $2.7 \mu \mathrm{M}$, respectively) relative to parental icSARS-CoV-2-mNG $(0.7 \mu \mathrm{M})$ (Figure 2e). Assessment of RDV cytotoxicity demonstrated limited impact on cell death rates below $10 \mu \mathrm{M}$, indicating that the RDV resistance phenotype conferred by mutations at E802 may occur at physiologically relevant concentrations (Fig S2c).

These findings suggest that RDV resistance mediated by substitutions at residue 802 in nsp12 may lead to therapeutic failure in the setting of an immunocompromisted host. We speculate that mutations at 802 distort the active site in a way that either enables the enzyme to exclude RDV or alleviates the steric clash mediated by S861, thereby allowing the enzyme to escape RDVmediated chain termination ${ }^{1,9}$. Further biochemical and structural characterization will be needed to delineate the mechanism by which substitutions at residue E802 confer resistance to RDV.

The therapeutic impact of RDV resistance mutations at E802 may be attenuated by a fitness cost imparted by these mutations, which we observed in vitro. Although RDV therapy has been 
widely administered to patients during the pandemic, E802D and all substitutions at residue 802 have been found in 131 and 297, respectively, of the 4.8M genome sequences obtained from patient isolates in the GISAID database (www.gisaid.org; accessed 11/07/21). Consistent with the observation of a fitness cost, the allele frequency of E802D in nasopharyngeal specimens from the patient decreased from $22.6 \%$ to $<1 \%$ between the period (day $160-162$ ) after completion of RDV therapy and prior to casirivimab-imdevimab administration (Figure $2 b$ ). However, E802 allele frequencies were significantly higher (50-96\% at days 158-167) in saliva specimens during this period and did not decline until casirivimab-imdevimab was administered.

An explanation for these discordant findings is unclear and may relate to the differential compartmentalization of variants within the respiratory tract or the stochastic nature of sampling the nasopharyngeal compartment as opposed to saliva where virus from a wider geographic distribution may pool. Given that saliva is infrequently sampled, RDV resistance mediated by E802 mutations may be under-detected. Furthermore, analysis of the 131 genomic sequences that have been found in GISAID to contain the E802D mutation identified two instances where sequences were geographically and temporally clustered, suggesting that local transmission of E802D variants may have occurred (Figure S3). Continued surveillance will thus be needed to elaborate whether the occurrence of E802D, as well as other substitutions at this residue, will be limited because of an underlying fitness cost or alternatively, emerge to pose a broader risk for RDV resistance.

We did not identify nsp 12 mutations at sites other than residue 802 which were temporally associated with RDV therapy. A mutation at D484Y has been reported in a post- treatment sample from an immunocompromised patient who failed RDV therapy ${ }^{11}$, but the RDV resistance phenotype associated with this mutation, whose location is distal to the active site, has not been 
confirmed. We identified two additional mutations, A504V in nsp14 (exonuclease) and I115L in nsp15 (endoRNAse), whose allele frequencies increased during and after RDV treatment (Figure S4). However, A504V in nsp14 was present (allele frequency 85.1\%) in a specimen obtained during her initial phase of illness (day 36). Although I115L in nsp15 was not detected in the early-phase specimen, the plausibility of a mutation in the endoRNAse gene which confers RDV resistance is less clear.

The case highlights additional issues for the management of SARS-CoV-2 infection in immunocompromised patients. Firstly, the course of infection was notable for being indolent despite a six-month period of sustained high-grade viral shedding and underlying lung involvement. We identified six mutations, including a frameshift mutation in ORF3a (N257fs), which were present throughout the course of illness prior to RDV treatment (Figure S5). Yet none provides a clear explanation for an attenuated phenotype. Longitudinal profiling of PBMC demonstrated profound depletion of circulating B-cell populations and a T-cell phenotype consistent with chronic antigen exposure as evidenced by the increased activation (CD38+, HLA-DR+) and exhaustion (PD-1, Tim-3) markers (Figure S6). Given reports that maladaptive immune responses contribute to the risk of severe COVID-19 12,13 , we speculate that the compromised immune response was unable to control viral load yet conversely, protected the patient from developing severe complications.

Secondly, SARS-CoV-2 infection was associated with the development of severe refractory neutropenia and moderate anemia in the patient (Figure 1c). While we are unable to discern if the cytopenia was due to direct or indirect effects of infection, SARS-CoV-2 has been detected in the bone marrow of an immunocompromised patient who developed pancytopenia during 
infection $^{14}$. Our patient's cytopenia resolved after casirivimab-imdevimab therapy, suggesting a causal link between SARS-CoV-2 infection and cytopenia in this setting.

Finally, the case illustrates the potential benefit of mAb therapy for immunocompromised patients with persistent SARS-CoV-2 infection. Prior to initiation of mAb therapy, two nonsynonymous mutations, H655Y (Figure S7a) and P812L (Figure S7b), emerged which were not present in the initial specimen (day 36), indicating that spike protein continues to evolve and adapt to the host in the absence of selective pressure from an adaptive immune response. One week after casirivimab-imdevimab was administered (day 170), we identified a new spike protein mutation, A348S in the RBD domain, which persisted to day 177 (Figure S7c). WGS was not performed on specimens collected after day 177 because of low amounts or undetectable viral RNA. A348S is not proximal to the mAb binding sites (Figure S7d) ${ }^{15}$ and was not identified in a comprehensive analysis of resistance mutations ${ }^{6}$. In the setting of a negligible cellular immune response, $\mathrm{mAb}$ therapy cleared viral shedding, abrogated the residual complaint of anosmia, and resolved the blood dyscrasias.

In summary, we identified the de novo emergence of a RDV-resistance mutation, E802D, following initiation of RDV in an immunocompromised patient with persistent SARS-CoV-2 infection. While the finding is limited to a single case and requires confirmation of its generalizability in larger patient populations, it suggests that RDV may impart a selective pressure in vivo to drive evolution of the virus. E802D is associated with a fitness cost in vitro, which may limit the broader impact of this mutation on the development of secondary resistance during treatment and the risk for primary resistance through transmission of resistant variants. Yet, our findings underscore the importance of immunocompromised hosts with uncontrolled viral replication as a source of genetic diversification ${ }^{3,4,16-18}$ and selection of mutations that may 
medRxiv preprint doi: https://doi.org/10.1101/2021.11.08.21266069; this version posted December 7, 2021. The copyright holder for this preprint (which was not certified by peer review) is the author/funder, who has granted medRxiv a license to display the preprint in perpetuity. All rights reserved. No reuse allowed without permission.

potentially impart adverse consequences for antiviral therapy. Enhanced genomic surveillance of immunocompromised patients may thus be warranted. As observed in this case, initiation of antiSARS-CoV-2 mAb may serve as a therapeutic option to achieve rapid and sustained virologic responses and improved clinical outcomes in immunocompromised patients. 


\section{Online Methods}

\section{Regulatory and ethical approvals}

Regulatory approval to administer an $8 \mathrm{~g}$ dose of casirivimab/imdevimab was obtained from the U.S. Food and Drug Administration under investigational new drug application no. 153390.

This study was also approved by Yale Human Research Protection Program Institutional Review Boards (FWA00002571, protocol ID 2000027690, 2000029277). Informed consent was obtained from both the patient and healthcare workers.

\section{RNA extraction and PCR}

RNA was extracted on a Qiagen Bio Robot (Qiagen, Hilden, Germany) using the QIAamp Virus Bio Robot MDx Kit (Qiagen) following manufacturer's instructions. RT-PCR was performed using AgPath-ID One-Step RT-PCR kit (Life Technologies, Carlsbad, CA, USA) with CDC primers and probes for N1/N2 following protocol and concentrations defined previously ${ }^{19}$. Each $25 \mu \mathrm{L}$ of reaction mix included $2 \mathrm{X}$ RT-PCR buffer, $25 \mathrm{X}$ enzyme mix, primers-probes, and $5 \mu \mathrm{L}$ of the extracted RNA. Cycle parameters on the ABI 7500 real-time PCR system (Applied Biosystems) were $10 \mathrm{~min}$ at $48^{\circ} \mathrm{C}$ for reverse transcription, $10 \mathrm{~min}$ of inactivation at $95^{\circ} \mathrm{C}, 40$ cycles of $15 \mathrm{sec}$ at $95^{\circ} \mathrm{C}$, and $45 \mathrm{sec}$ at $60^{\circ} \mathrm{C}$. Internal control (EXO), positive, and negative (water) control were included on every run.

\section{Library preparation and sequencing}

Using $11 \mu \mathrm{L}$ of extracted RNA, single strand complementary DNA (sscDNA) was synthesized using SuperScript IV First-Strand Synthesis System (Thermofisher). Sequencing libraries were prepared using the Swift Normalase Amplicon Panel (SNAP) for SARS-CoV-2 (Swift 
medRxiv preprint doi: https://doi.org/10.1101/2021.11.08.21266069; this version posted December 7, 2021. The copyright holder for this preprint (which was not certified by peer review) is the author/funder, who has granted medRxiv a license to display the preprint in perpetuity.

All rights reserved. No reuse allowed without permission.

Biosciences, Ann Arbor, MI, USA) as described previously ${ }^{8}$. Libraries were quantified using fluorometric methods (Quant-iT dsDNA high sensitivity kit, Life Technologies, Carlsbad, CA, USA), normalized, and sequenced on the Illumina NextSeq 500 or 2000 instruments (Illumina, San Diego, CA, USA) using 2x150 reads.

\section{Analysis of sequencing data}

Reads were processed using a custom bioinformatic pipeline (https://github.com/greninger$\underline{\text { lab/covid_swift_pipeline), as described }}{ }^{8}$. Briefly, raw FASTQs were trimmed of adapter content and low-quality reads, then aligned to the NCBI reference Wuhan-1 (NC_045512). PCR primers were soft-clipped with Primerclip (https://github.com/swiftbiosciences/primerclip) and a consensus genome was generated from this alignment using bcftools v1.9 ${ }^{20}$. Variants were examined longitudinally with a modified Python script adapted from LAVA (https://github.com/greninger-lab/lava).

A k-mer based approach was used to identify reads corresponding to subgenomic RNAs. After removing adapters and low-quality regions, junction-spanning reads corresponding to individual sgRNAs were filtered using BBDuk (https://sourceforge.net/projects/bbmap/) against a custom FASTA file composed of 30 nucleotides of the 5' leader sequence and 30 nucleotides of the respective 3' junctions of downstream $\mathrm{ORFs}^{21}$, allowing an edit distance of 1 . In order to avoid calling of genomic reads, we constrained matches to those that had 10 consecutive matches of 31 mers.

\section{Isolation of patient plasma and PBMCs}


As described previously, patient whole blood was collected in sodium heparin-coated vacutainers and gently agitating at room temperature until sample pick-up by IMPACT team members. All blood was processed on the day of collection. Plasma samples were collected after centrifugation of whole blood at $400 \mathrm{~g}$ for 10 minutes at room temperature (RT) without brake. The undiluted serum was then transferred to $15-\mathrm{ml}$ polypropylene conical tubes, and aliquoted and stored at $-80{ }^{\circ} \mathrm{C}$ for subsequent analysis. PBMCs were isolated using Histopaque (Sigma-Aldrich, \#10771-500ML) density gradient centrifugation in a biosafety level $2+$ facility. After isolation of undiluted serum, blood was diluted 1:1 in room temperature PBS, layered over Histopaque in a SepMate tube (StemCell Technologies; \#85460) and centrifuged for 10 minutes at 1,200g. The PBMC layer was isolated according to the manufacturer's instructions. Cells were washed twice with PBS before counting. Pelleted cells were briefly treated with an ACK lysis buffer for 2 minutes and then counted. Percentage viability was estimated using standard Trypan blue staining and an automated cell counter (Thermo-Fisher, \#AMQAX1000).

\section{Flow cytometry}

As described previously ${ }^{22}$, antibody clones and vendors used for flow cytometry analysis were as follows: BB515 anti-hHLA-DR (G46-6) (1:400) (BD Biosciences), BV605 anti-hCD3 (UCHT1) (1:300) (BioLegend), BV785 anti-hCD4 (SK3) (1:200) (BioLegend), APCFire750 or PE-Cy7 or BV711 anti-hCD8 (SK1) (1:200) (BioLegend), BV421 anti-hCCR7 (G043H7) (1:50)

(BioLegend), AlexaFluor 700 anti-hCD45RA (HI100) (1:200) (BD Biosciences), PE anti-hPD1 (EH12.2H7) (1:200) (BioLegend), APC anti-hTIM3 (F38-2E2) (1:50) (BioLegend), BV711 antihCD38 (HIT2) (1:200) (BioLegend), BB700 anti-hCXCR5 (RF8B2) (1:50) (BD Biosciences), PE-Cy7 anti-hCD127 (HIL-7R-M21) (1:50) (BioLegend) and PE-CF594 anti-hCD25 (BC96) 
medRxiv preprint doi: https://doi.org/10.1101/2021.11.08.21266069; this version posted December 7, 2021. The copyright holder for this preprint (which was not certified by peer review) is the author/funder, who has granted medRxiv a license to display the preprint in perpetuity.

All rights reserved. No reuse allowed without permission.

(1:200) (BD Biosciences). In brief, freshly isolated PBMCs were plated at $1-2 \times 10^{6}$ cells per well in a 96-well U-bottom plate. Cells were resuspended in Live/Dead Fixable Aqua (ThermoFisher) for $20 \mathrm{~min}$ at $4{ }^{\circ} \mathrm{C}$. Following a wash, cells were blocked with Human TruStan FcX (BioLegend) for 10 min at RT. Cocktails of desired staining antibodies were added directly to this mixture for $30 \mathrm{~min}$ at RT. For reinfection stains, cells were first washed and supernatant aspirated; then to each cell pellet a cocktail of secondary markers was added for 30 min at $4{ }^{\circ} \mathrm{C}$. Prior to analysis, cells were washed and resuspended in $100 \mu \mathrm{l} \%$ PFA for $30 \mathrm{~min}$ at $4{ }^{\circ} \mathrm{C}$. Following this incubation, cells were washed and prepared for analysis on an Attune NXT (ThermoFisher). Data were analysed using FlowJo software version 10.6 software (Tree Star). The specific sets of markers used to identify each subset of cells are summarized in ${ }^{20}$ Figure S6.

\section{SARS-CoV-2 specific-antibody measurements}

ELISAs were performed as previously described ${ }^{23}$. Triton X-100 and RNase A were added to serum samples at final concentrations of $0.5 \%$ and $0.5 \mathrm{mg} / \mathrm{ml}$ respectively and incubated at room temperature (RT) for 30 minutes. 96-well MaxiSorp plates (Thermo Scientific \#442404) were coated with $50 \mu \mathrm{l} /$ well of recombinant SARS Cov-2 S1 protein (ACROBiosystems \#S1NC52H3-100ug) at a concentration of $2 \mu \mathrm{g} / \mathrm{ml}$ in PBS and were incubated overnight at $4{ }^{\circ} \mathrm{C}$. The coating buffer was removed, and plates were incubated for $1 \mathrm{~h}$ at RT with $200 \mu \mathrm{l}$ of blocking solution (PBS with 0.1\% Tween-20, 3\% milk powder). Serum was diluted 1:50 in dilution solution (PBS with $0.1 \%$ Tween-20, 1\% milk powder) and $100 \mu 1$ of diluted serum was added for two hours at RT. Plates were washed three times with PBS-T (PBS with 0.1\% Tween-20) and 50 $\mu 1$ of HRP anti-Human IgG Antibody (GenScript \#A00166, 1:5,000) diluted in dilution solution added to each well. After $1 \mathrm{~h}$ of incubation at RT, plates were washed three times with PBS-T. 
medRxiv preprint doi: https://doi.org/10.1101/2021.11.08.21266069; this version posted December 7, 2021. The copyright holder for this preprint (which was not certified by peer review) is the author/funder, who has granted medRxiv a license to display the preprint in perpetuity.

All rights reserved. No reuse allowed without permission.

Plates were developed with $100 \mu$ of TMB Substrate Reagent Set (BD Biosciences \#555214)

and the reaction was stopped after $15 \mathrm{~min}$ by the addition of $2 \mathrm{~N}$ sulfuric acid. Plates were read at a wavelength of $450 \mathrm{~nm}$ and $570 \mathrm{~nm}$.

\section{Cell lines and virus}

As previously described ${ }^{22}$, Vero E6 kidney epithelial cells were cultured in Dulbecco's Modified Eagle Medium (DMEM) supplemented with 1\% sodium pyruvate (NEAA) and 5\% fetal bovine serum (FBS) at $37^{\circ} \mathrm{C}$ and $5 \% \mathrm{CO} 2$. The cell line was obtained from the ATCC and has been tested negative for contamination with mycoplasma. SARS-CoV-2, strain USA-WA1/2020, was obtained from BEI Resources (\#NR-52281) and was amplified in Vero E6 cells. Cells were infected at a MOI 0.01 for four three days to generate a working stock and after incubation the supernatant was clarified by centrifugation $(450 \mathrm{~g} \times 5 \mathrm{~min})$ and filtered through a 0.45 -micron filter. The pelleted virus was then resuspended in PBS then aliquoted for storage at $-80^{\circ} \mathrm{C}$. Viral titers were measured by standard plaque assay using Vero E6 cells. All experiments were performed in a biosafety level 3 with the Yale Environmental Health and Safety office approval.

\section{Virus titration from nasopharyngeal swabs.}

SARS-CoV-2 titers from longitudinal nasopharyngeal swabs were assessed by conventional plaque assay. Nasopharyngeal swabs were collected and swabs stored and frozen in universal viral transport media (VTM) prior to plaquing. Each nasopharyngeal sample was ten-fold serially diluted (dilution range from 1:10 to 1:1000000). Diluted NP samples were added on a monolayer of Vero E6 cells. After 1 hour of infection, DMEM (2\% FBS), and 1.2\% of Avicel (Dupont, 9004346) were overlaid. 72 hours post inoculation, media was removed and 4\% 
medRxiv preprint doi: https://doi.org/10.1101/2021.11.08.21266069; this version posted December 7, 2021. The copyright holder for this preprint (which was not certified by peer review) is the author/funder, who has granted medRxiv a license to display the preprint in perpetuity.

All rights reserved. No reuse allowed without permission.

Paraformaldehyde added for 1 hour. Cells were stained with $0.1 \%$ of crystal violet to visualize SARS-CoV-2 plaques. Plaques were counted by single operator. Each sample was tested in duplicate.

\section{Site-directed mutagenesis and full length icSARS-CoV-2 mNG E802D and E802A}

\section{production.}

The reverse genetics system used to generate E802D and E802A SARS-CoV-2 mutants is described at length elsewhere ${ }^{10}$. The icSARS-CoV-2 mNG (mNeonGreen) backbone previously reported was employed to construct both full-length E802D and E802A mutant viruses utilizing the following primer pairs: forward (E802D): gttggactgaTactgaccttactaaaggac, reverse (E802D): aggtcagtAtcagtccaacatttgcttc; and forward (E802A):

gttggactgCgactgaccttactaaaggac, reverse (E802A): aggtcagtcGcagtccaacatttgcttc. Site-directed mutagenesis was performed using Pfu Turbo Polymerase (Agilent) according to manufacturer's instructions. E802D and E802A mutations were confirmed in icSARS-CoV-2 mNG backbone by Sanger sequencing using the primer: gatgatactctctgacgatg.

Steps to produce full-length infectious virus were performed as described previously ${ }^{10}$, with the following minor modifications: Plasmid propagation and digestion were performed as described and excision of DNA bands from the gel was done by using a Blue-Light transilluminator (Accuris). Next, equal molar amounts of the seven plasmids were reduced by half relative to the prior reports to perform the full-length genomic ligation: F1 (.305 $\mu \mathrm{g}), \mathrm{F} 2(.325 \mu \mathrm{g}), \mathrm{F} 3(.375$ $\mu \mathrm{g}), \mathrm{F} 4(.47 \mu \mathrm{g})$ were ligated using T4 DNA ligase with a final volume of $50 \mu 1$. Plasmids F5 $(.375 \mu \mathrm{g}), \mathrm{F} 6(.36 \mu \mathrm{g})$ and F7 $(.3 \mu \mathrm{g})$ were incubated with T4 DNase Ligase in a volume of $40 \mu \mathrm{l}$. 
The primary reactions were incubated at $4{ }^{\circ} \mathrm{C}$ for $16 \mathrm{~h}$. After this, the two reactions were mixed and volumed up to $100 \mu \mathrm{l}$ by adding the corresponding additional volume of ligation reagents. The secondary ligation was incubated for $18 \mathrm{~h}$ at $4^{\circ} \mathrm{C}$. The full-length genomes were purified by using the Genomic DNA Clean and Concentrator kit from Zymo Research according to manufacturer's instructions. Successful ligation products were visualized using a $0.8 \%$ agarose gel and standard gel imager.

Next, full-length in vitro RNA transcription was also performed with additional modifications. First, 500 ng of each ligation product was employed. Reactions were performed using the mMESSAGE mMACHINE T7 Transcription Kit (Thermo Scientific) with a cap analog-to-GTP ratio of $1: 1$. Incubation of the reaction was done at $32^{\circ} \mathrm{C}$ for $12 \mathrm{~h}$. Following DNAse treatment was performed at $37^{\circ} \mathrm{C}$ for $15 \mathrm{~min}$. Next, viral RNA was purified by using the RNA Clean and Concentrator kit from Zymo Research according to the manufacturer's instructions. Successful transcription products were visualized using a $0.8 \%$ agarose gel and standard gel imager.

RNA transcripts were next electroporated into BHK-N expressing cells (courtesy of Dr. Brett Lindenbach). $15 \mu \mathrm{g}$ of each mutant transcript was electroporated into BHK cells using the Electro Square Porator Device (BTX). Electroporated cells were seeded into a T75 flask containing 1:2 ratio of BHK-N:Vero-E6 cells. Complete monolayer CPE was evident at $72 \mathrm{~h}$ post-electroporation and supernatant was centrifuged and .22 um filtered. Vero-E6 were infected with $500 \mathrm{uL}$ of each of the clarified supernatants. Supernatants were collected for each mutant virus at 48 hours post infection and tittered as described previously. Infectious clones are available with MTA and appropriate biosafety approvals. 


\section{Sequencing and variant calling}

RNA was extracted from SARS-CoV-2 mutants using the MagMAX viral/pathogen nucleic acid isolation kit and tested with the multiplexed RT-qPCR variant assay ${ }^{24}$. Using a standard dilution series, $\mathrm{Ct}$ values were converted to RNA copies per $\mu \mathrm{L}$. Extracted RNA was diluted to 1 million copies per $\mu \mathrm{L}$ and used as input into the COVIDSeq Test RUO version for library preparation, in duplicate. Pooled libraries were sequenced on the NovaSeq (paired-end 150) at the Yale Center for Genome Analysis. Single nucleotide variants were called at a minimum frequency threshold of 0.02 and minimum read depth of $400 \mathrm{X}$ using iVar (version 1.3.1) ${ }^{25}$, and filtered between duplicate replicates. Introduction of the E802D and E802A was confirmed at a minimum frequency of 0.82-0.9 in initial stocks.

\section{Replication kinetics of icSARS-CoV-2 mutants.}

Isolates from initial stocks were expanded and used to infect Vero-E6 cells with $0.01 \mathrm{MOI}$ of each E802D and E802A mutant virus to assess their replication kinetics. Supernatants were collected at 8, 24 and 48 hours post-infection. Titers for each time point were assessed by conventional plaque assay as described above. Each virus was assessed in triplicate.

\section{Remdesivir resistance assay.}

Each icSARS-CoV-2 mutant virus (E802D and E802A) was cultured in the presence of increasing concentrations of RDV, ranging from 0.39 to $40 \mu \mathrm{M}$. Infections were performed using Vero-E6 in 384-well plates containing the corresponding RDV dilutions in phenol-red free DMEM media with $5 \% \mathrm{FBS}$ and incubated at $37^{\circ} \mathrm{C}$ for 4 hours. Next, cells were infected with 
medRxiv preprint doi: https://doi.org/10.1101/2021.11.08.21266069; this version posted December 7, 2021. The copyright holder for this preprint (which was not certified by peer review) is the author/funder, who has granted medRxiv a license to display the preprint in perpetuity.

All rights reserved. No reuse allowed without permission.

0.01 MOI of each mutant virus and infected cell frequencies were measured at 48 hours postinfection by mNeonGreen expression by high content imaging (Cytation 5, BioTek $)^{26}$. Cell culture supernatants were also collected for plaque assay. Cell viability in uninfected cells was assessed at $72 \mathrm{~h}$ post-infection using the CellTiter-Glo kit (Promega) according to the manufacturer's instructions.

\section{Neutralization assay}

As described previously ${ }^{27}$, patient sera was isolated from whole blood and heat treated for 30 minutes at $56^{\circ} \mathrm{C}$. Sixfold serially diluted plasma, from 1:10 to 1:2430 were incubated with SARS-CoV-2 for $1 \mathrm{~h}$ at $37^{\circ} \mathrm{C}$. The mixture was subsequently incubated with Vero E6 cells in a 6-well plate for 1 hour for infection. Cells were overlayed with DMEM supplemented $\mathrm{NaHCO}_{3}$, $2 \% \mathrm{FBS}$, and $0.6 \%$ Avicel mixture ${ }^{26}$. Plaques were resolved at $40 \mathrm{~h}$ post infection by fixing in $4 \%$ formaldehyde for $1 \mathrm{~h}$ followed by staining in $0.5 \%$ crystal violet. All experiments were performed in parallel with healthy, uninfected control sera to establish degree of protection as reflected in difference in plaque counts.

\section{Phylogenetic analysis}

Phylogenic trees were generated using the Nextstrain software package ${ }^{28} .326$ background sequences from CT, USA collected April $1^{\text {st }}$-September $30^{\text {th }} 2020$ were downloaded from GISAID (Supplemental Table 3). The tree was rooted using the Wuhan reference strain. Genome sequences which contain the E802D mutation were identified from the GISAID database (accessed on 10/31/21; Supplemental Table 4) and were compared to sequences in the global Auspice dataset. 


\section{Data availability}

Sequencing data are available under NCBI BioProject no. PRJNA774781 (Supplementary Table 2).

\section{Acknowledgements}

The authors thank Dr. Michael Jacobs, Dr. Sanjay Bhagani and Dr. David Lowe at the Royal Free Hospital for their advice regarding the management of the patient, Dr. Jennifer Hamilton, David Stein, Dr. Wendy Kampman and Dr. David M. Weinreich at Regeneron Pharmaceuticals, Inc. for their guidance on the use of monoclonal antibody therapy and laboratory evaluations, Nathanial Price at Yale School of Medicine for his assistance in identifying data and samples for the analyses, and Dr. Chantal Vogels, Dr. Joseph Fauver, Mallery Breban and Dr. Nathan Grubaugh at the Yale School of Public Health for sequencing infectious clones and providing advice on the analysis and interpretation of the genomic data. Casirivimab and imdevimab was provided by Regeneron Pharmaceuticals, Inc. for the purpose of emergency compassionate use treatment. We also thank the health care staff at Yale New Haven Hospital, which include Dr. Jensa Morris, Dr. Anne Spichler, Dr. Frederick Altice and Dr. Nikhil Seval, who cared for the patient during her hospital course and provided key input, and most of all, the patient for her equanimity and contributions to this study.

This study was supported by the Beatrice Kleinberg Neuwirth Fund; the Sendas Family Fund, Yale School of Public Health; and Department of Internal Medicine at the Yale School of Medicine. SG was supported by a grant from the National Institutes of Health (2T32AI007517- 
21A1). C.B.W. was supported by Burroughs Welcome Fund, Ludwig Family Foundation, and Mathers Foundation.

\section{Contributions}

J.K., A.R., and M.P.H contributed to data collection, analysis, and writing. M.L., P.R., J.F., D. F., C.V., M.C.M., A.S., E.W, N.K., P.L, W.W., A.P. contributed to data collection and analysis. B.L. contributed to study design. O.O., A.G, C.B.W, A.I., and W.L.S. conceived of the study and contributed to study design, interpretation, and editing of the manuscript. S.G. and A.I.K conceived of the study and contributed to study design, data interpretation, writing, and regulatory approvals.

\section{Competing Interests}

ALG reports institutional central testing contracts from Abbott and research grants from Merck and Gilead, outside of the proposed work. AIK received consulting fees from Tata Sons and is recipient of grants on COVID-19 from Merck, Regeneron and Serimmune all of which are outside the submitted work. OO received consulting fees from Gilead and ViiV, as well as research support and honoraria from Gilead, outside of the submitted work. WLS is a consultant for Hugo Health, founder of Refactor Health and is recipient of grants on COVID-19 from Merck and Regeneron, all of which are outside the submitted work.

\section{References}

1. Kokic, G. et al. Mechanism of SARS-CoV-2 polymerase stalling by remdesivir. Nat Commun 12, 279 (2021). 
2. Szemiel, A. M. et al. In vitro selection of Remdesivir resistance suggests evolutionary predictability of SARS-CoV-2. Plos Pathog 17, e1009929 (2021).

3. Collaboration, T. C.-N. B. C.-19 et al. SARS-CoV-2 evolution during treatment of chronic infection. Nature 1-10 (2021) doi:10.1038/s41586-021-03291-y.

4. Choi, B. et al. Persistence and Evolution of SARS-CoV-2 in an Immunocompromised Host. New Engl J Med 383, 2291-2293 (2020).

5. Collaboration, C.-N. C.-19 B. et al. Treatment of COVID-19 with remdesivir in the absence of humoral immunity: a case report. Nat Commun 11, 6385 (2020).

6. Baum, A. et al. Antibody cocktail to SARS-CoV-2 spike protein prevents rapid mutational escape seen with individual antibodies. Science 369, 1014-1018 (2020).

7. Baum, A. et al. REGN-COV2 antibodies prevent and treat SARS-CoV-2 infection in rhesus macaques and hamsters. Science eabe2402 (2020) doi:10.1126/science.abe2402.

8. Addetia, A. et al. Sensitive Recovery of Complete SARS-CoV-2 Genomes from Clinical Samples by Use of Swift Biosciences' SARS-CoV-2 Multiplex Amplicon Sequencing Panel. J Clin Microbiol 59, (2020).

9. Yin, W. et al. Structural basis for inhibition of the RNA-dependent RNA polymerase from SARS-CoV-2 by remdesivir. Science 368, 1499-1504 (2020).

10. Xie, X. et al. Engineering SARS-CoV-2 using a reverse genetic system. Nat Protoc 16, 1761-1784 (2021).

11. Martinot, M. et al. Remdesivir failure with SARS-CoV-2 RNA-dependent RNA-polymerase mutation in a B-cell immunodeficient patient with protracted Covid-19. Clin Infect Dis ciaa1474(2020) doi:10.1093/cid/ciaa1474.

12. Wang, E. Y. et al. Diverse Functional Autoantibodies in Patients with COVID-19. doi:10.1101/2020.12.10.20247205.

13. Wilk, A. J. et al. A single-cell atlas of the peripheral immune response in patients with severe COVID-19. Nat Med 26, 1070-1076 (2020).

14. Issa, N., Lacassin, F. \& Camou, F. First case of persistent pancytopenia associated with SARS-CoV-2 bone marrow infiltration in an immunocompromised patient. Ann Oncol 31, 14181419 (2020).

15. Hansen, J. et al. Studies in humanized mice and convalescent humans yield a SARS-CoV-2 antibody cocktail. Science 369, 1010-1014 (2020). 
16. Drouin, A. C. et al. Successful Clearance of 300 Day SARS-CoV-2 Infection in a Subject with B-Cell Depletion Associated Prolonged (B-DEAP) COVID by REGEN-COV Anti-Spike Monoclonal Antibody Cocktail. Viruses 13, 1202 (2021).

17. Avanzato, V. A. et al. Case Study: Prolonged infectious SARS-CoV-2 shedding from an asymptomatic immunocompromised cancer patient. Cell (2020) doi:10.1016/j.cell.2020.10.049.

18. Clark, S. A. et al. SARS-CoV-2 evolution in an immunocompromised host reveals shared neutralization escape mechanisms. Cell (2021) doi:10.1016/j.cell.2021.03.027.

19. Corman, V. M. et al. Detection of 2019 novel coronavirus (2019-nCoV) by real-time RTPCR. Eurosurveillance 25, 2000045 (2020).

20. Li, H. A statistical framework for SNP calling, mutation discovery, association mapping and population genetical parameter estimation from sequencing data. Bioinformatics 27, 2987-2993 (2011).

21. Alexandersen, S., Chamings, A. \& Bhatta, T. R. SARS-CoV-2 genomic and subgenomic RNAs in diagnostic samples are not an indicator of active replication. Nat Commun 11, 6059 (2020).

22. Lucas, C. et al. Longitudinal analyses reveal immunological misfiring in severe COVID-19. Nature 584, 463-469 (2020).

23. Amanat, F. et al. A serological assay to detect SARS-CoV-2 seroconversion in humans. Nat Med 26, 1033-1036 (2020).

24. Vogels, C. B. F. et al. Multiplex qPCR discriminates variants of concern to enhance global surveillance of SARS-CoV-2. Plos Biol 19, e3001236 (2021).

25. Grubaugh, N. D. et al. An amplicon-based sequencing framework for accurately measuring intrahost virus diversity using PrimalSeq and iVar. Genome Biol 20, 8 (2019).

26. Wei, J. et al. Genome-wide CRISPR Screens Reveal Host Factors Critical for SARS-CoV-2 Infection. Cell 184, 76-91.e13 (2021).

27. Lucas, C. et al. Delayed production of neutralizing antibodies correlates with fatal COVID19. Nat Med 27, 1178-1186 (2021).

28. Hadfield, J. et al. Nextstrain: real-time tracking of pathogen evolution. Bioinformatics 34, 4121-4123 (2018). 
medRxiv preprint doi: https://doi.org/10.1101/2021.11.08.21266069; this version posted December 7, 2021. The copyright holder for this preprint (which was not certified by peer review) is the author/funder, who has granted medRxiv a license to display the preprint in perpetuity.

All rights reserved. No reuse allowed without permission.

Figures

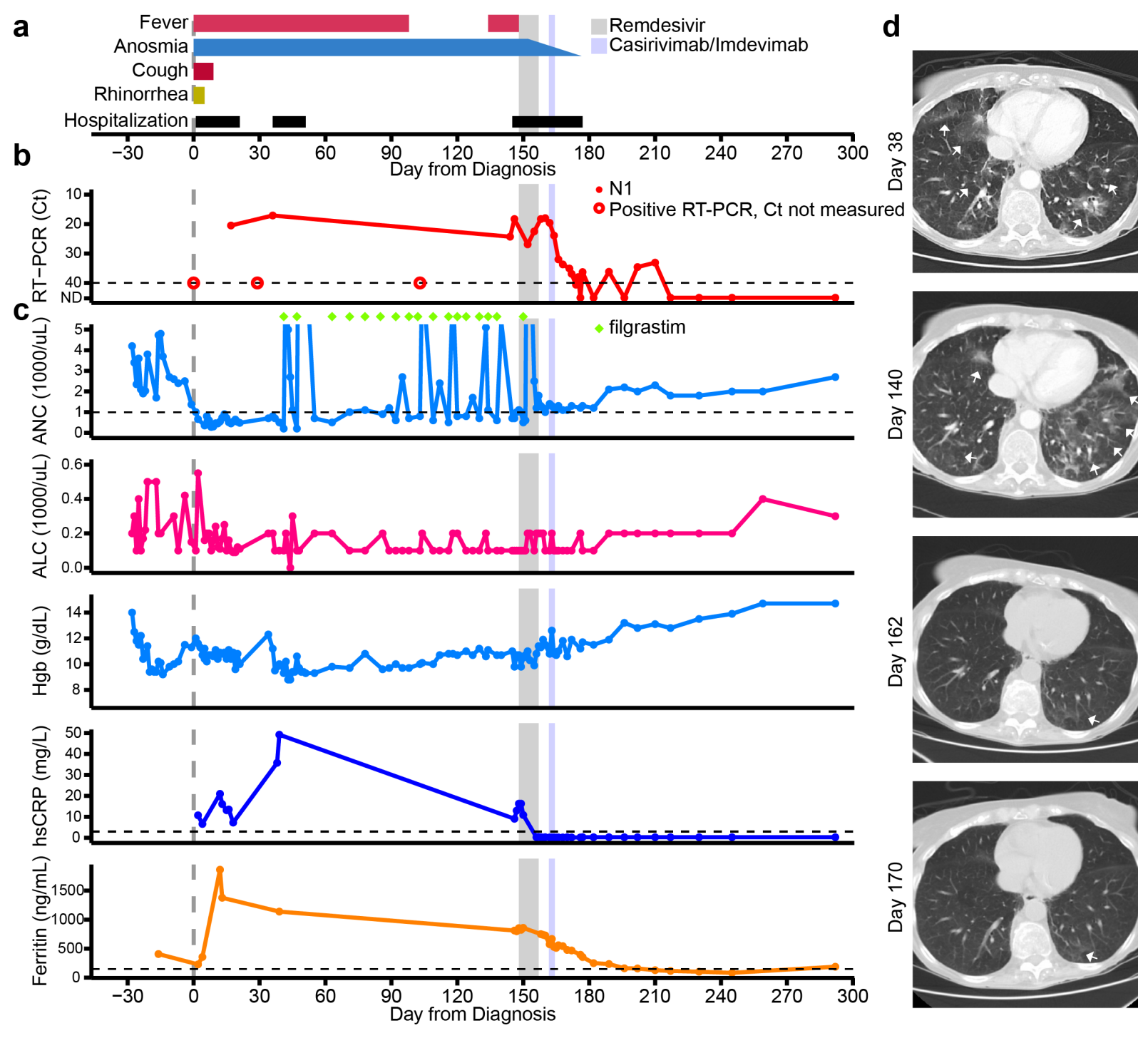

Fig. 1: Clinical course of the immunocompromised patient with persistent SARS-CoV-2

\section{infection}

Timeline of a) patient symptoms and hospitalizations, b) SARS-CoV-2 N1 RT-PCR Ct values and c) clinical laboratory parameters from time of laboratory diagnosis of SARS-CoV-2 infection (day 0) to end of the follow-up period (day 292) and d) computed tomography (CT) scans of chest at indicated days after time of initial diagnosis. The timing of remdesivir and 
casirivimab-imdevimab are shown as grey and light blue shading, respectively. RT-PCR results that were positive but performed on assays that did not generate a $\mathrm{Ct}$ value are denoted by the open circle in panel $\mathrm{b}$. The timing of filgrastim treatments are denoted by green diamonds in panel b. lsCRP values were converted to hsCRP values using a correction factor of 9.2. Groundglass opacities marked by white arrows in panel d. Abbreviations: Real-time polymerase chain reaction (RT-PCR); Cycle threshold (Ct); Absolute neutrophil count (ANC); Absolute lymphocyte count (ALC); Hemoglobin (Hgb); high-sensitivity C-reactive protein (hsCRP). 

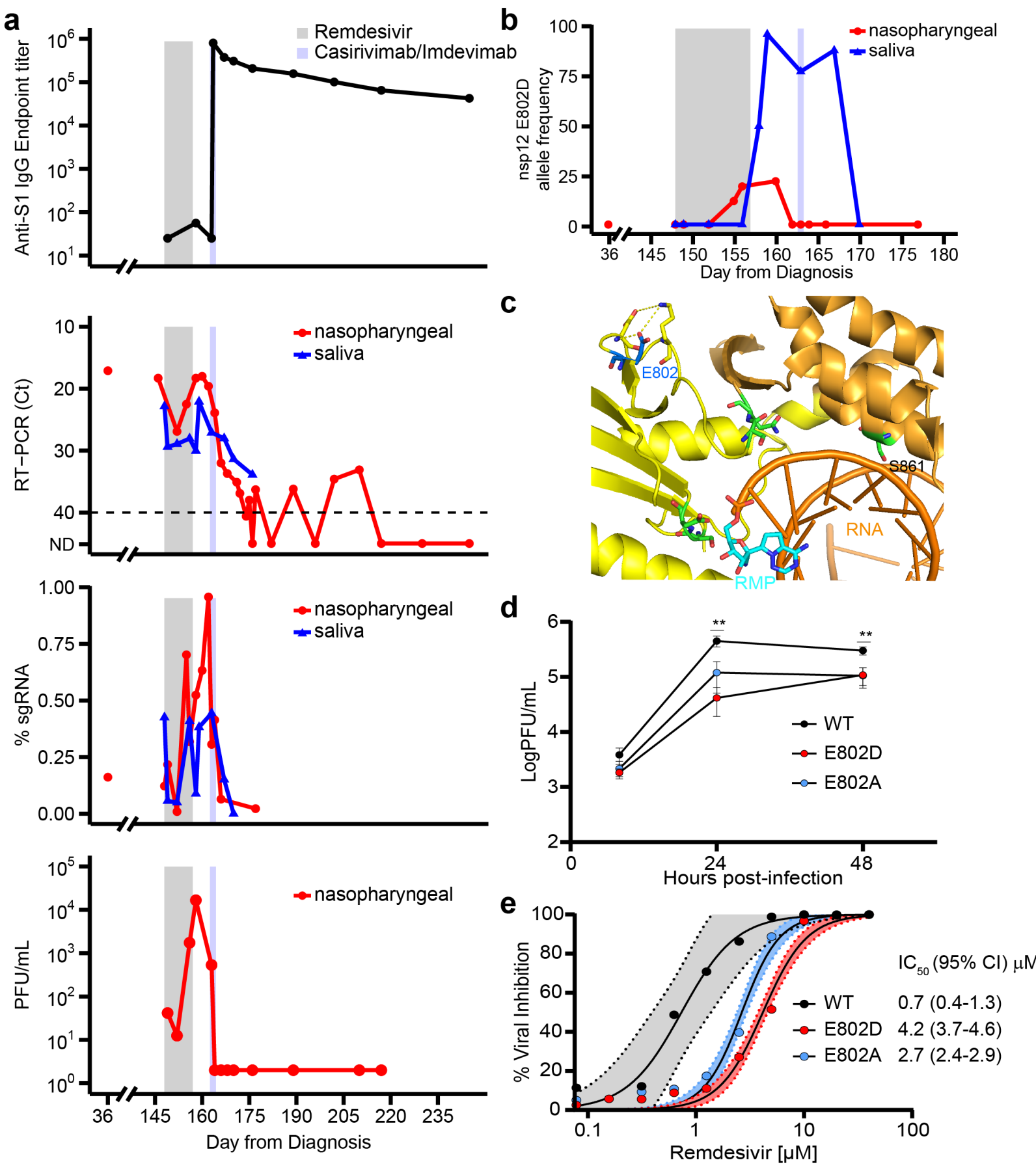

Fig. 2: de novo emergence of remdesivir resistance mutation during and following

\section{treatment with the antiviral agent}

a) Anti-SARS-CoV-2 Spike Protein IgG ELISA endpoint titers (1st panel), RT-PCR Ct values

( $2^{\text {nd }}$ panel), subgenomic RNA (sgRNA, $3^{\text {rd }}$ panel), and plaque forming units (PFU) on viral 
culture (4th panel) during the course of illness which include the period when remdesivir (grey shading) and casirivimab/imdevimab (light blue shading) were administered. b) Allele frequencies of E802D in nsp12 as ascertained by whole genome sequencing. c) Crystal structure (PDB:7BV2) depicting nsp12 E802 (dark blue), its putative hydrogen bonds (yellow dashed lines) within the palm domain (yellow), and the residues (green) that interact with the replicating RNA molecule (orange). Remdesivir monophosphate (RMP) is depicted in light blue. d) Viral growth curves from icSARS-CoV-2 mNG WT, E802D (patient), and E802A (control) nsp12 mutants on a ORF7a depleted backbone. Significance was assessed by unpaired two sample ttests $(* * \mathrm{p}<0.01)$ in experiments of three biological replicates. e) SARS-CoV-2 inhibition by RDV assessed at $48 \mathrm{~h}$ post-infection ( 0.01 multiplicity of infection) as determined by quantitative image analysis of percentage of cells expressing $\mathrm{mNG}$. Vertical lines indicate $\mathrm{IC}_{50}$ for WT (black) and E802D (red). Shading represents 95\% confidence intervals of the $\mathrm{IC}_{50}$ estimate. Figure is representative of four biological replicates. 


\section{Supplemental Material}

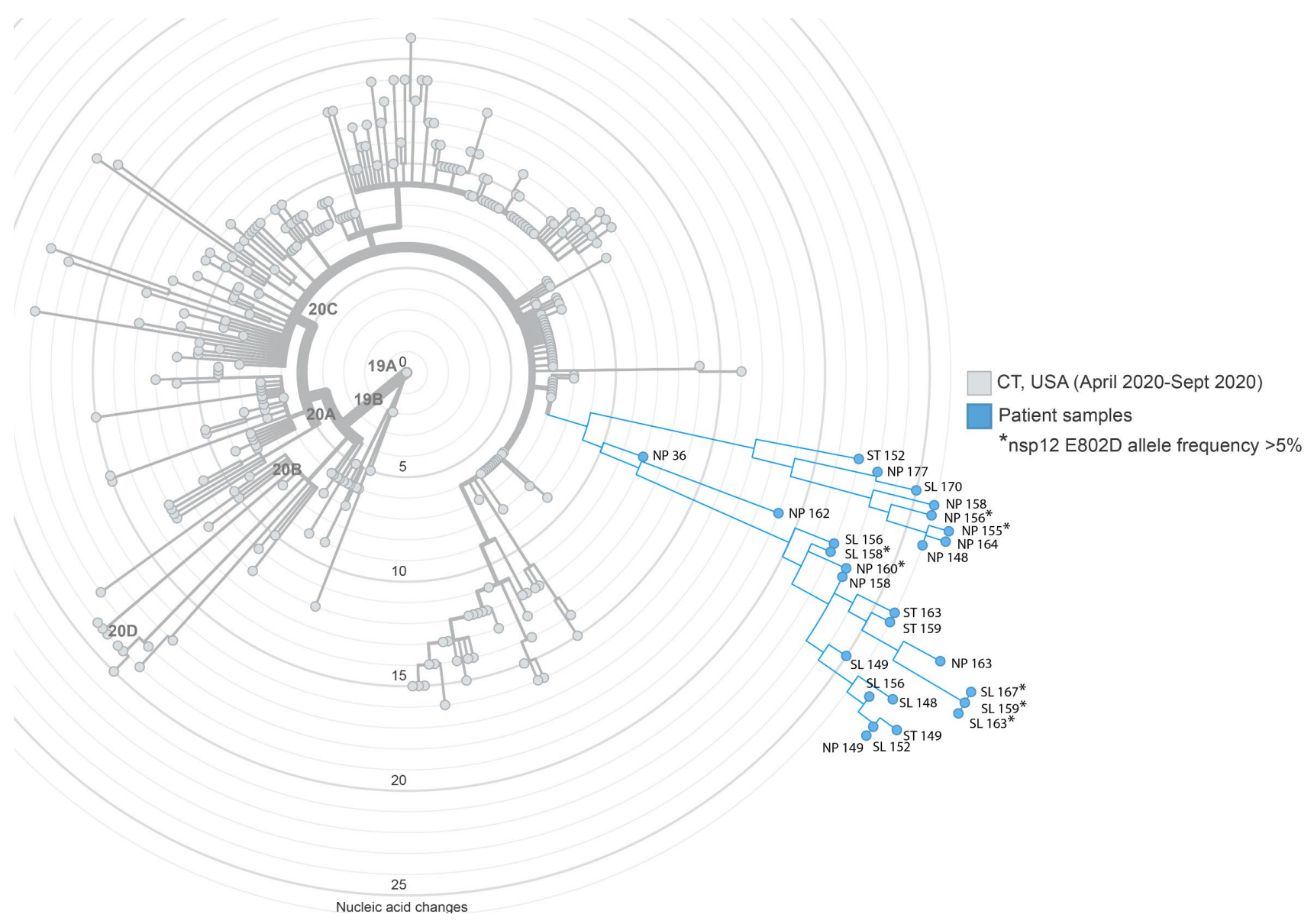

Fig. S1: Phylogenetic analysis of SARS-CoV-2 genomes from patient samples and contemporaneous samples from Connecticut, USA.

Nextstrain maximum likelihood analysis of patient whole genome samples (blue) in comparison to 283 contemporaneous local samples (grey) obtained from GISAID (10/30/21; Supplemental Table 3). Samples are annotated by type (nasopharyngeal (NP), saliva (SL), or stool (ST)) and day from diagnosis. Asterisk denotes consensus genomes that contain nsp12 E802D. Divergence from root reference genome (Wuhan-Hu-1) by nucleic acid changes. 


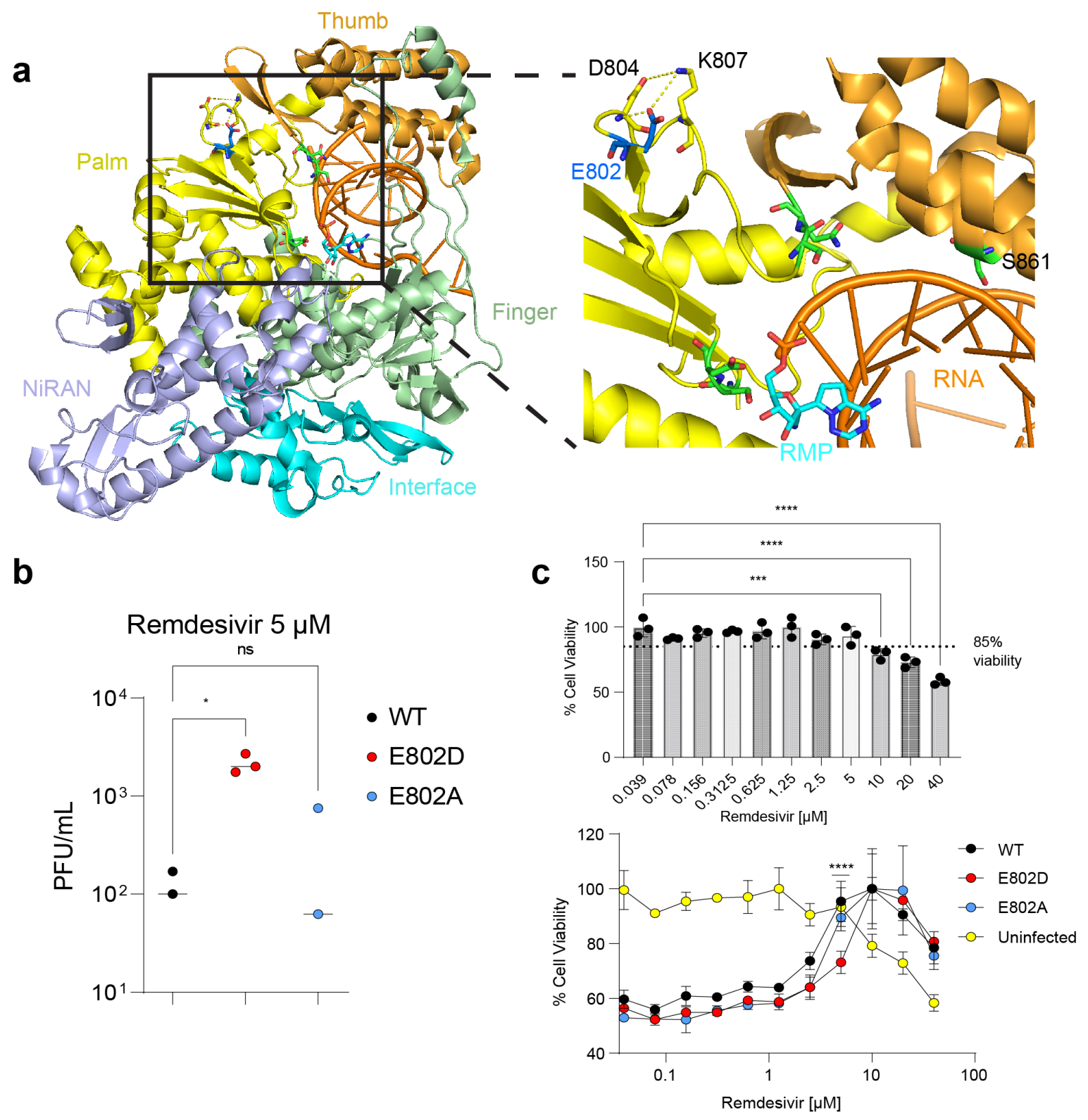

Fig. S2: Validation of a remdesivir resistance mutation

a) Structure depicting E802 in relationship to nsp12 (PDB:7BV2) b) Viral titers (PFU) assessed under $5 \mu \mathrm{M}$ RDV treatment. Significance was assessed by an ANOVA $(* p<0.05)$ with 3 biological replicates. c) Cell viability experiment with RDV performed using CellTiter Glo. Significance of infected cells with SARS-CoV-2 WT (top panel) or E802D/A (bottom panel) was assessed by two-way ANOVA corrected for multiple comparisons (**** $p<0.0001$ ) with 3 biological replicates. 


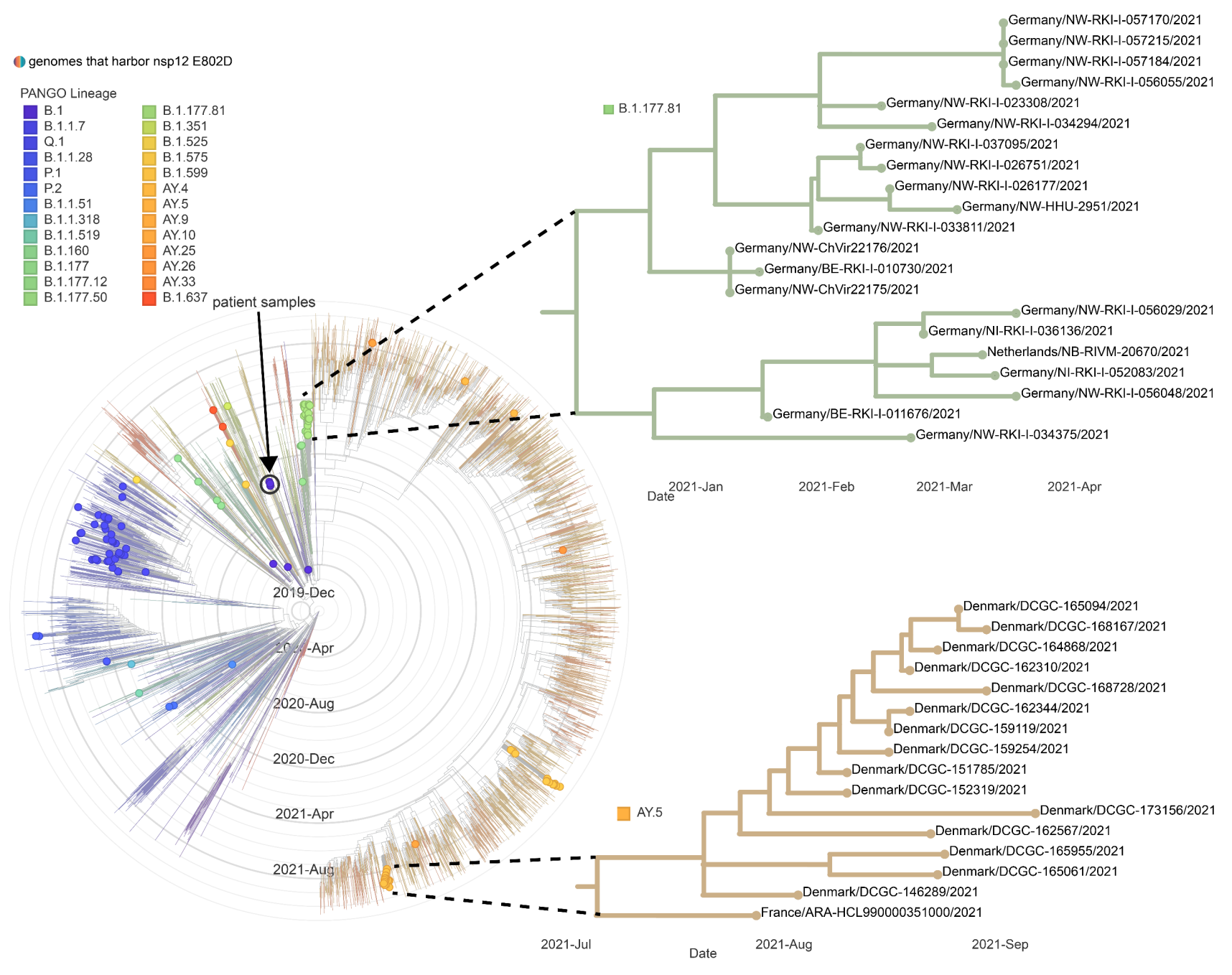

Fig. S3: Global analysis of genomes with nsp12 E802D mutations.

Nextstrain maximum likelihood analysis of 131 genomes containing the E802D mutation in comparison to the global representative Auspice dataset. Genomes with the E802D mutation (denoted by circles) are distributed on various PANGO lineages (color coded according to the legend). The four patient genomes harboring the mutation are denoted by the arrow. Two genetically, geographically, and temporally linked networks are depicted in detail. 


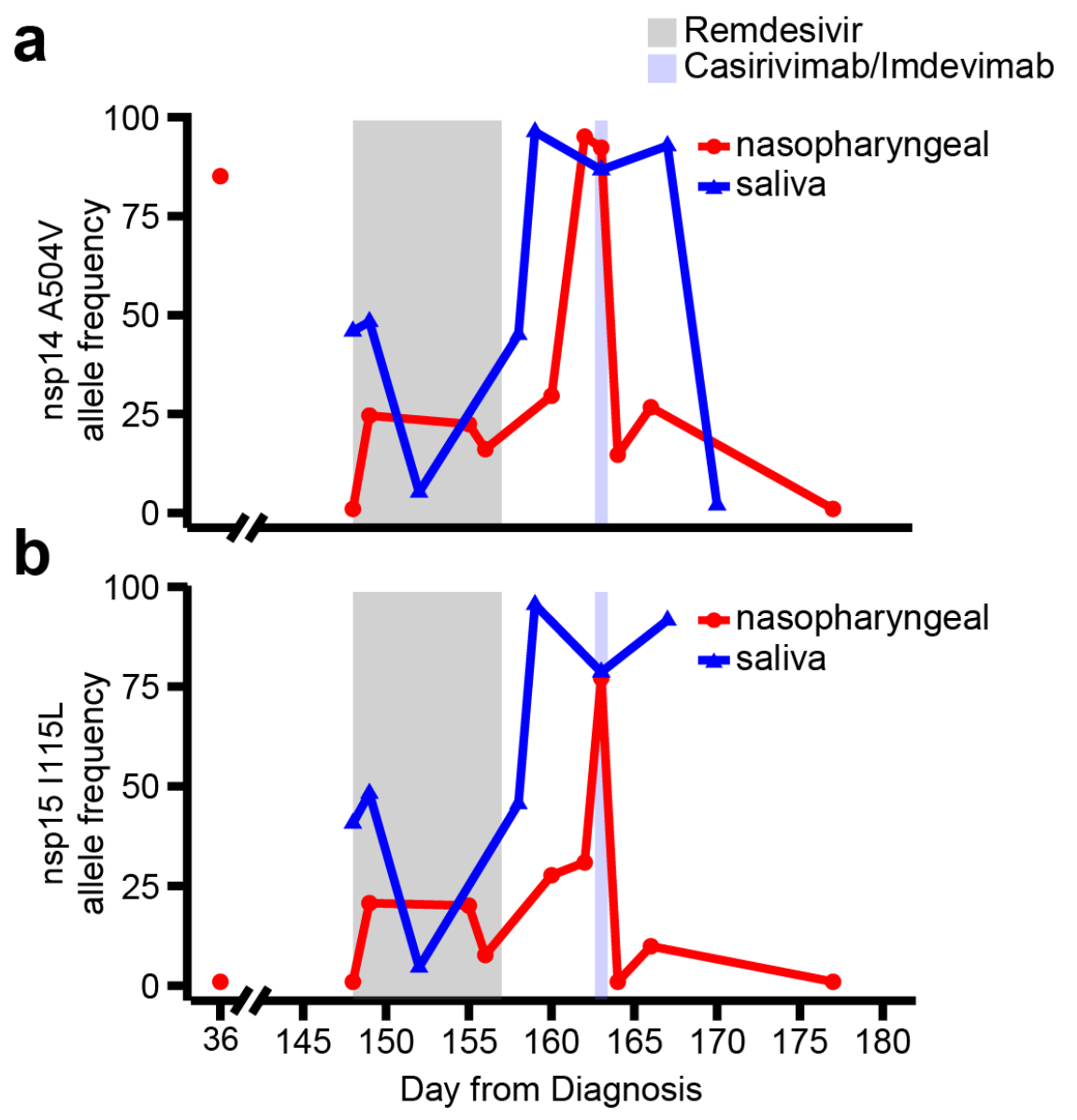

Fig S4: Identification of additional mutations temporally associated with remdesivir treatment

Longitudinal allele frequencies of A504V in nsp14 (a) and I115L (b) by whole genome sequencing of in relationship to RDV and casirivimab/imdevimab 


\begin{tabular}{|c|c|c|c|c|c|}
\hline SNP & Protein & AA & NP 36 & NP 148 & SL 148 \\
\hline G521T & leader protein & V86F & & & $x$ \\
\hline G569A & leader protein & E102K & & $x$ & \\
\hline C1059T & nsp2 & T85I & $\mathrm{x}$ & $\mathrm{x}$ & $\mathrm{x}$ \\
\hline A4229G & nsp3 & T504A & & $x$ & \\
\hline C4230G & nsp3 & T504R & & & $x$ \\
\hline C5178T & nsp3 & T8201 & $x$ & & $x$ \\
\hline G5180A & nsp3 & D821N & & $x$ & \\
\hline С9344T & nsp4 & L264F & & & $x$ \\
\hline С9870Т & nsp4 & T439M & & $x$ & \\
\hline G9929A & nsp4 & D459N & & & $x$ \\
\hline A10323G & 3C-like_proteinase & K90R & & $x$ & \\
\hline G11083T & nsp6 & L37F & & & $x$ \\
\hline A12519G & nsp8 & D143G & & $x$ & \\
\hline $\mathrm{C} 12525 \mathrm{~T}$ & nsp8 & T145I & & & $x$ \\
\hline A12759G & nsp9 & D25G & & $x$ & \\
\hline A12759C & nsp9 & D25A & & & $x$ \\
\hline C14408T & $\operatorname{RdRp}$ & P323L & $\mathrm{x}$ & $\mathrm{x}$ & $x$ \\
\hline C19550T & 3'-to-5' exonuclease & A504V & $x$ & & \\
\hline A23403G & surface glycoprotein & D614G & $\mathrm{x}$ & $\mathrm{x}$ & $x$ \\
\hline $\mathrm{C} 23525 \mathrm{~T}$ & surface glycoprotein & H655Y & & & $x$ \\
\hline C23997T & surface glycoprotein & $\mathrm{P} 812 \mathrm{~L}$ & & $x$ & \\
\hline C25511T & ORF3a_protein & S40L & & & $x$ \\
\hline G25563T & ORF3a_protein & Q57H & $\mathrm{x}$ & $\mathrm{x}$ & $\mathrm{x}$ \\
\hline $\mathrm{C} 25714 \mathrm{~T}$ & ORF3a_protein & L108F & & $x$ & \\
\hline G25912T & ORF3a_protein & G174C & & $x$ & \\
\hline A26162del & ORF3a_protein & N257fs & $x$ & $x$ & $x$ \\
\hline T26767C & membrane glycoprotein & $182 \mathrm{~T}$ & & $x$ & \\
\hline$A 28281 G$ & nucleocapsid & D3G & & $x$ & \\
\hline T28829C & nucleocapsid & $\mathrm{S} 186 \mathrm{P}$ & & & $x$ \\
\hline C28472A & nucleocapsid & P67T & $\mathrm{x}$ & $\mathrm{x}$ & $x$ \\
\hline G29151A & nucleocapsid & R293K & $x$ & & \\
\hline A29567G & ORF10_protein & $14 \mathrm{~V}$ & & & $x$ \\
\hline
\end{tabular}


medRxiv preprint doi: https://doi.org/10.1101/2021.11.08.21266069; this version posted December 7, 2021. The copyright holder for this preprint (which was not certified by peer review) is the author/funder, who has granted medRxiv a license to display the preprint in perpetuity.

\section{Fig. S5: Variants identified in persistently infected host}

Non-synonymous (NS) mutations identified at days 36 (NP) and 148 (NP and saliva) of infection. During early infection (day 36), whole genome sequencing identified 9 NS mutations from reference strain Wuhan-1 (NC_045512). Six of those persisted through day 148 (green background). Abbreviations: single nucleotide polymorphism (SNP); amino acid (AA); nasopharyngeal (NP); saliva (SL) 
medRxiv preprint doi: https://doi.org/10.1101/2021.11.08.21266069; this version posted December 7, 2021. The copyright holder for this preprint (which was not certified by peer review) is the author/funder, who has granted medRxiv a license to display the preprint in perpetuity.

All rights reserved. No reuse allowed without permission.

a
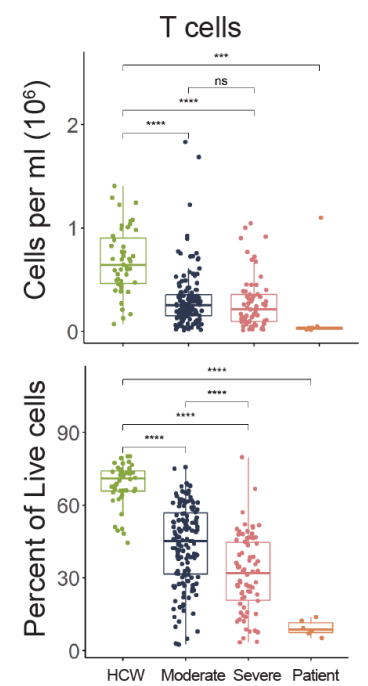
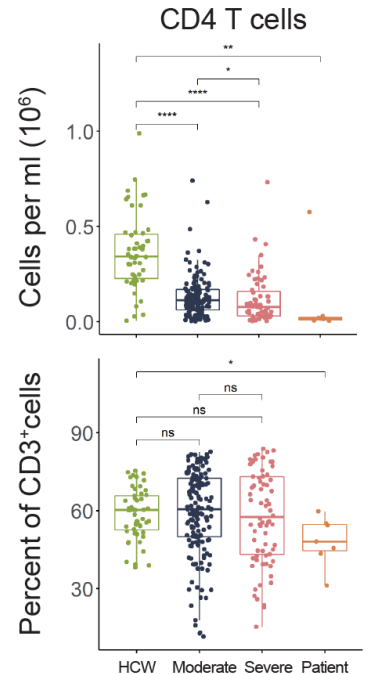
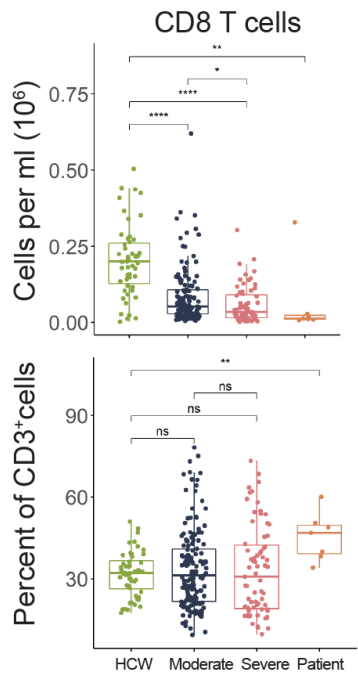

b
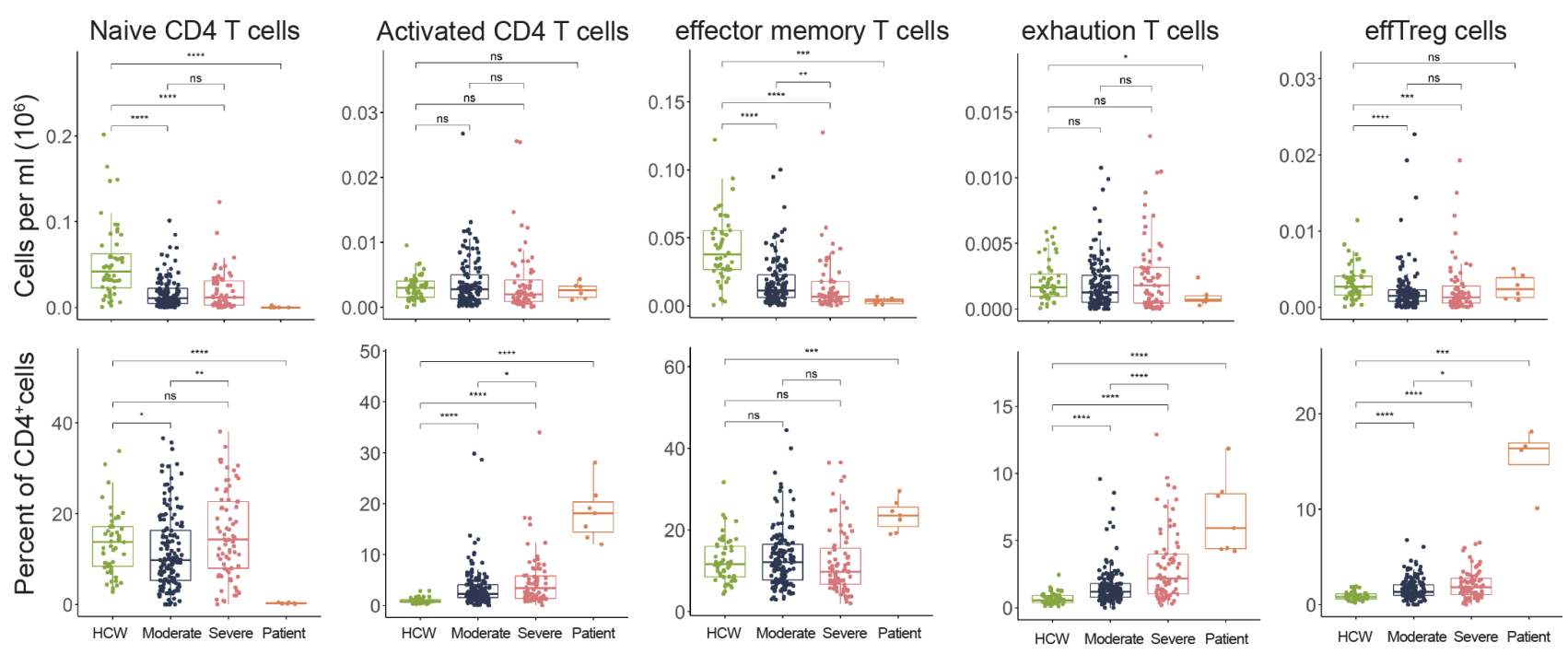

C
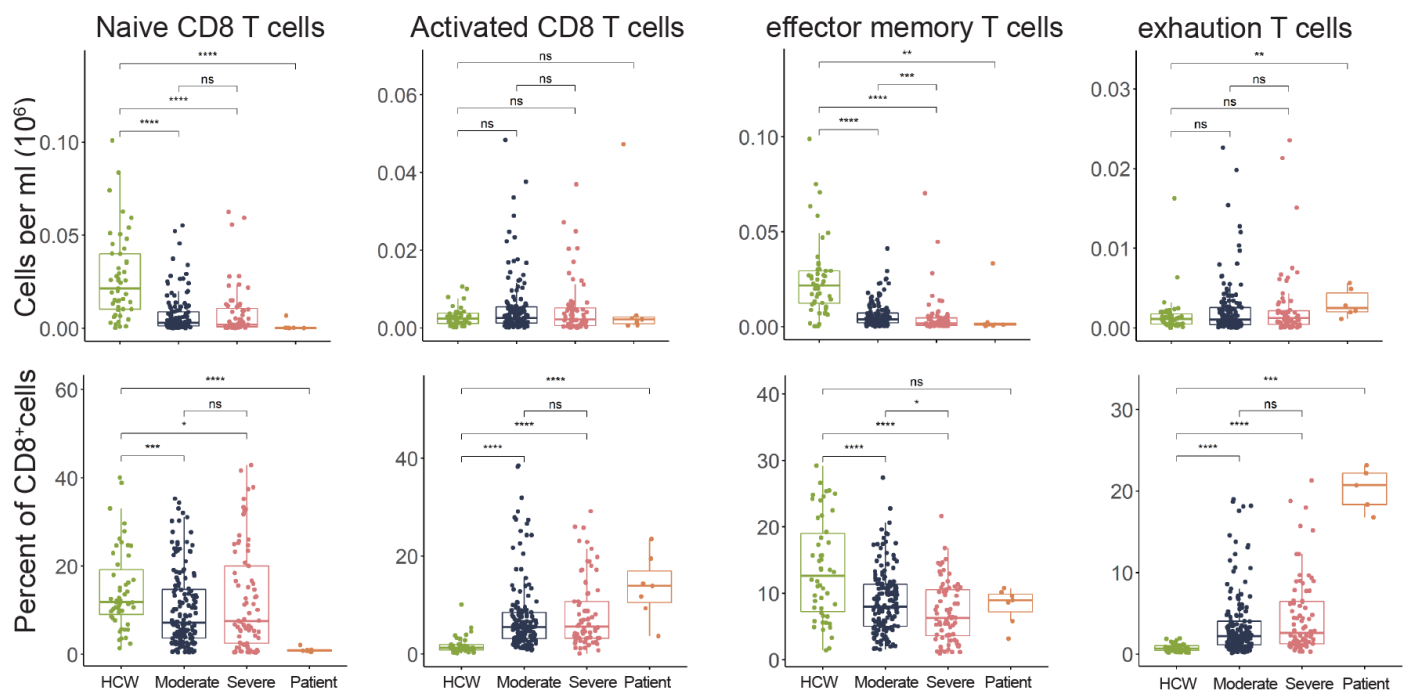


\section{Fig. S6: Serial lymphocyte profiling reveals T-cell exhaustion}

T-cell profiling of uninfected healthcare workers (HCW), patient's with moderate and severe SARS-CoV-2 infection. a) Global, CD4 ${ }^{+}$, and $\mathrm{CD}^{+}{ }^{+}$-cells. $\mathrm{CD}^{+}(\mathrm{b})$ and $\mathrm{CD}^{+}(\mathrm{c})$ subsets demonstrates a phenotype consistent with T-cell exhaustion. For all boxplots, the centre is drawn through the median of the measurement, while the lower and upper bounds of the box correspond to the first and third percentile. Whiskers beyond these points denote $1.5 \times$ the interquartile range.

$\mathrm{P}$ values were determined by two-sided, Wilcoxon rank-sum test. $* * * * \mathrm{p}<.0001 * * * \mathrm{p}<.001 * * \mathrm{p}$ $<.01 .{ }^{*} \mathrm{p}<.05$. Population definitions: naïve CD4/CD8 subset:

CD4/CD8+CD45RA+CD127+CCR7+PD-1-; activated CD4/CD8: CD4/CD8+CD38+HLADR+;effector memory CD4/CD8:CD4/CD8CD45RA-CD127+CCR7-; exhaustion CD4/CD8: CD4/CD8CD45RA-Tim-3+PD-1+; effTreg: CD4+CD45RA-CD127-CD25hiHLA-DR+. Gating strategy depicted in Fig S8. 
a

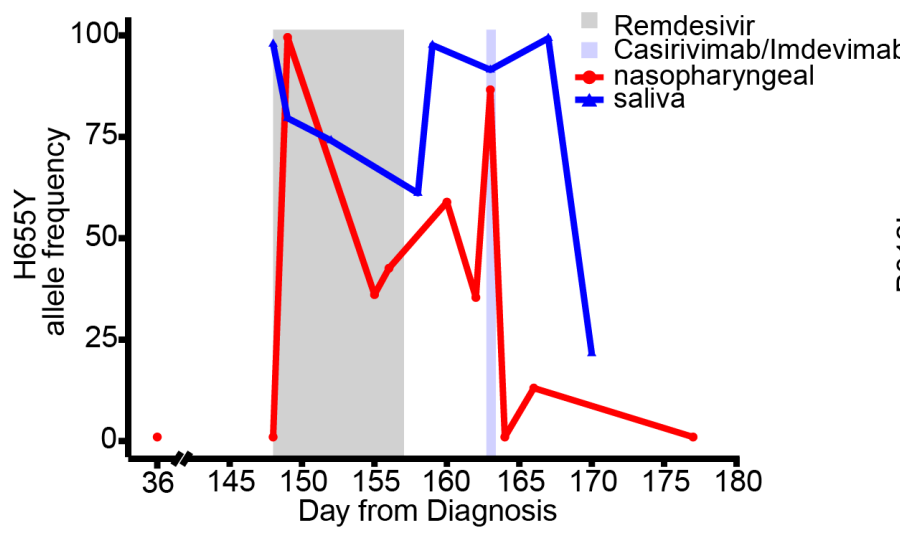

b

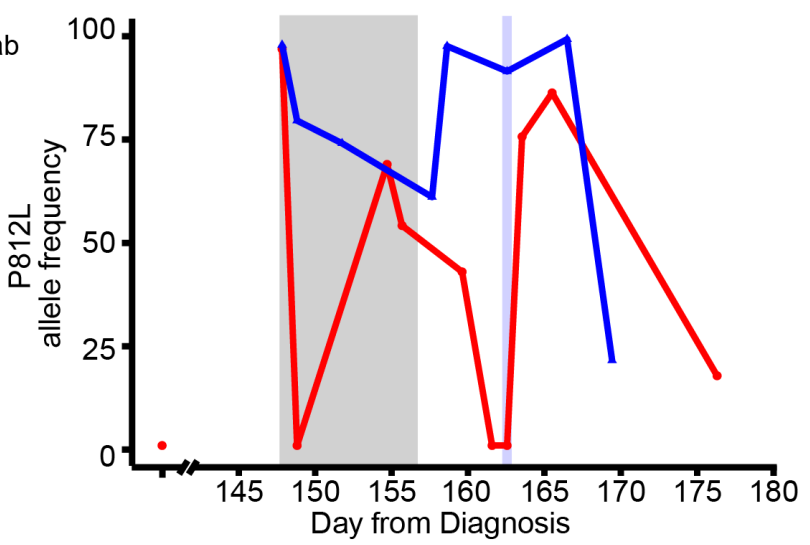

\begin{tabular}{|c|c|c|c|c|c|c|c|c|c|c|}
\hline Source & Day & D80Y & L141fs & A348S & D614G & V635G & H655Y & V656I & P812L & G1124V \\
\hline NP & 36 & $<5$ & $<5$ & $<5$ & 100 & $<5$ & $<5$ & $<5$ & $<5$ & $<5$ \\
\hline NP & 148 & $<5$ & $<5$ & $<5$ & 99.9 & $<5$ & $<5$ & $<5$ & 96.9 & $<5$ \\
\hline $\mathrm{SL}$ & 148 & $<5$ & $<5$ & $<5$ & 99.9 & $<5$ & 97.9 & $<5$ & $<5$ & $<5$ \\
\hline $\mathrm{NP}$ & 149 & $<5$ & $<5$ & $<5$ & 99.9 & $<5$ & 99.5 & $<5$ & $<5$ & $<5$ \\
\hline $\mathrm{SL}$ & 149 & $<5$ & $<5$ & $<5$ & 99.9 & 5.6 & 79.6 & $<5$ & 20.7 & $<5$ \\
\hline $\mathrm{SL}$ & 152 & $<5$ & $<5$ & 8.8 & 99.8 & $<5$ & 74.1 & $<5$ & $<5$ & $<5$ \\
\hline $\mathrm{NP}$ & 155 & $<5$ & $<5$ & $<5$ & 99.8 & $<5$ & 36.1 & 7.9 & 69 & $<5$ \\
\hline $\mathrm{NP}$ & 156 & $<5$ & $<5$ & $<5$ & 99.8 & $<5$ & 42.6 & $<5$ & 54.2 & $<5$ \\
\hline $\mathrm{SL}$ & 158 & $<5$ & $<5$ & $<5$ & 99.9 & 6.2 & 61.1 & $<5$ & 20.9 & $<5$ \\
\hline $\mathrm{NP}$ & 160 & $<5$ & $<5$ & $<5$ & 99.8 & $<5$ & 58.9 & $<5$ & 42.3 & $<5$ \\
\hline $\mathrm{NP}$ & 162 & 62.9 & $<5$ & $<5$ & 99.8 & $<5$ & 35.4 & 24.3 & $<5$ & 65.5 \\
\hline $\mathrm{NP}$ & 163 & 13.9 & $<5$ & $<5$ & 99.8 & $<5$ & 86.6 & 59.2 & $<5$ & 15.8 \\
\hline $\mathrm{SL}$ & 163 & $<5$ & $<5$ & $<5$ & 100 & 5.3 & 91.5 & 11.3 & 10.4 & $<5$ \\
\hline $\mathrm{NP}$ & 164 & 17.9 & 12.6 & $<5$ & 99.9 & $<5$ & $<5$ & $<5$ & 75.7 & 17.3 \\
\hline $\mathrm{NP}$ & 166 & $<5$ & $<5$ & $<5$ & 100 & $<5$ & 13.1 & 13.2 & 86.3 & 8.6 \\
\hline $\mathrm{SL}$ & 167 & $<5$ & $<5$ & $<5$ & 100 & 5.4 & 99.3 & 7.4 & $<5$ & $<5$ \\
\hline $\mathrm{SL}$ & 170 & $<5$ & 5.6 & 75 & 100 & 5.4 & 21.6 & $<5$ & $<5$ & $<5$ \\
\hline $\mathrm{NP}$ & 177 & $<5$ & $<5$ & 86.5 & 100 & $<5$ & $<5$ & $<5$ & 17.9 & $<5$ \\
\hline
\end{tabular}

d

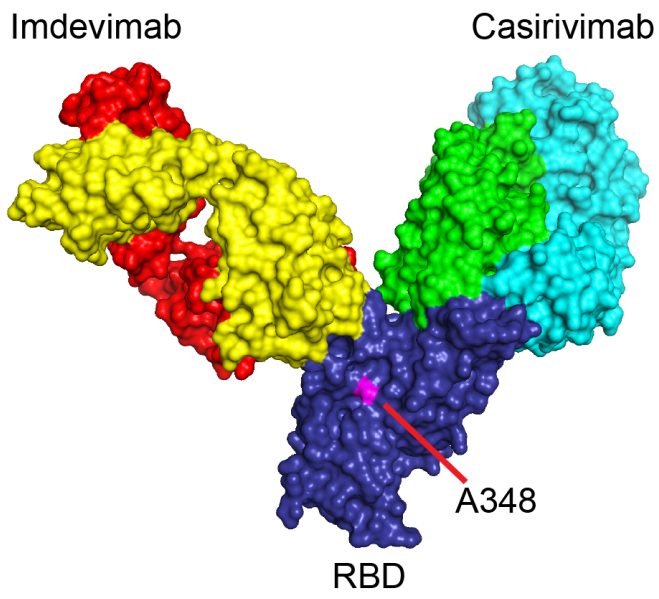


medRxiv preprint doi: https://doi.org/10.1101/2021.11.08.21266069; this version posted December 7, 2021. The copyright holder for this preprint (which was not certified by peer review) is the author/funder, who has granted medRxiv a license to display the preprint in perpetuity.

\section{Fig. S7: Evolution of Spike protein in patient samples.}

a) H655Y and b) P812L allele frequency over time. c) Allele frequencies of non-synonymous Spike protein mutations identified on more than one occasion by whole genome sequencing. Allele frequencies $>50 \%$ are denoted by green background. d) Crystral structure of RBD (PDB:6XDG) depicting residue A348 in relationship to the imdevimab (heavy chain: yellow; light rain: red) and casirivimab (heavy chain: green; light chain: blue) binding sites. Abbreviations: nasopharyngeal (NP); saliva (SL); receptor binding domain (RBD). 
medRxiv preprint doi: https://doi.org/10.1101/2021.11.08.21266069; this version posted December 7, 2021. The copyright holder for this preprint (which was not certified by peer review) is the author/funder, who has granted medRxiv a license to display the preprint in perpetuity.

All rights reserved. No reuse allowed without permission.
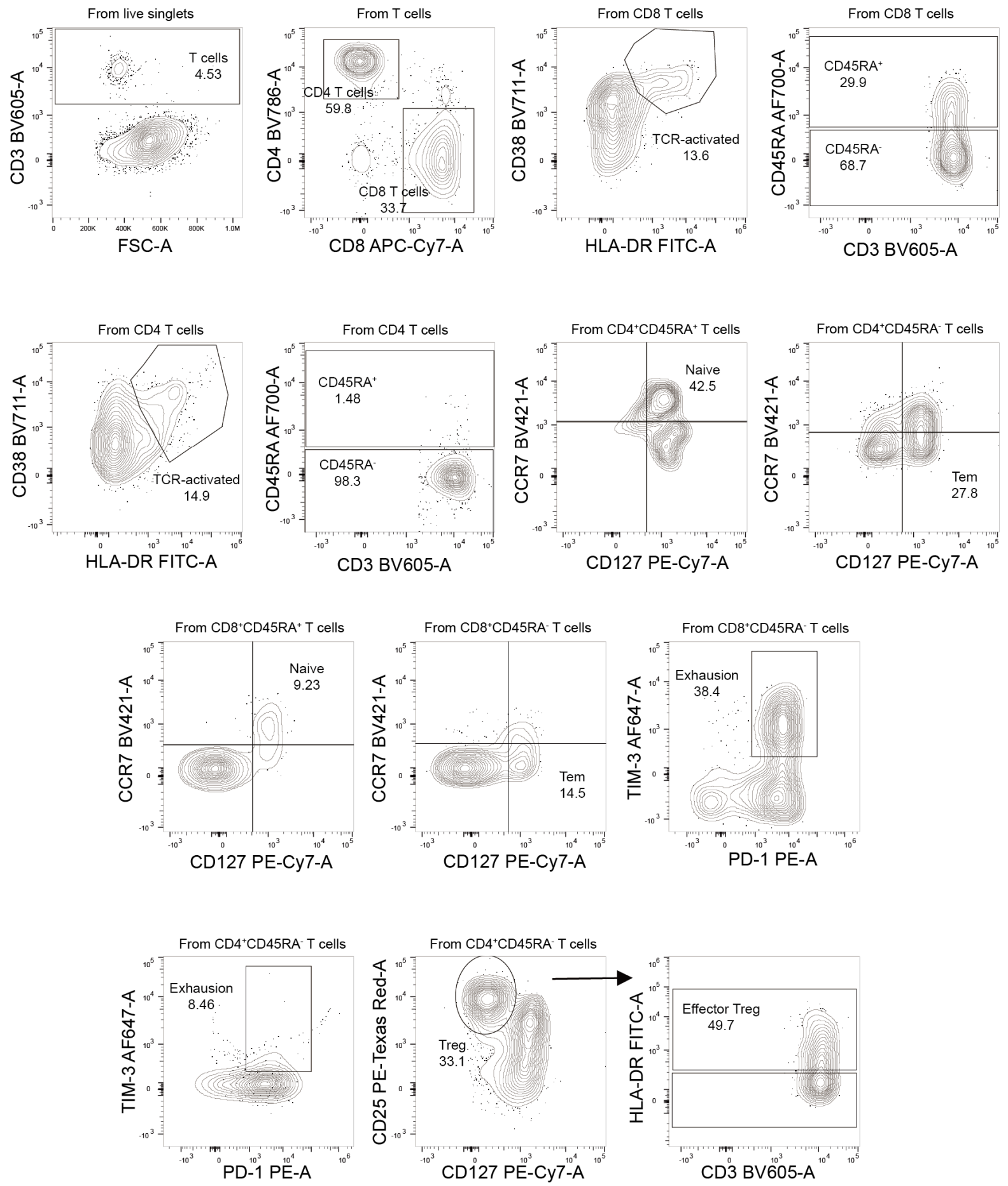
medRxiv preprint doi: https://doi.org/10.1101/2021.11.08.21266069; this version posted December 7, 2021. The copyright holder for this preprint (which was not certified by peer review) is the author/funder, who has granted medRxiv a license to display the preprint in perpetuity.

All rights reserved. No reuse allowed without permission.

\section{Figure S8: Gating strategy for flow cytometry}

Gating strategies are shown for the key T cell populations described in Figure S6. The T cell surface staining gating strategy to identify CD8 \& CD4 T cells, naïve T cells, TCR-activated T cells, exhaustion $\mathrm{T}$ cells, effector memory $\mathrm{T}$ cells $(\mathrm{Tem})$, and effector regulatory $\mathrm{T}$ cells (eff Treg) are depicted. 
medRxiv preprint doi: https://doi.org/10.1101/2021.11.08.21266069; this version posted December 7, 2021. The copyright holder for this preprint (which was not certified by peer review) is the author/funder, who has granted medRxiv a license to display the preprint in perpetuity.

All rights reserved. No reuse allowed without permission.

\begin{tabular}{|c|c|c|c|c|c|c|c|c|c|c|c|c|c|}
\hline \multirow[b]{2}{*}{$\begin{array}{l}\text { Days after } \\
\text { diagnosis }\end{array}$} & \multicolumn{4}{|c|}{ Nasopharyngeal specimen } & \multicolumn{3}{|c|}{ Saliva specimen } & \multicolumn{3}{|c|}{ Stool specimen } & \multicolumn{3}{|c|}{ Whole blood specimen } \\
\hline & $\begin{array}{l}\text { N1 RT- } \\
\text { PCR Ct }\end{array}$ & $\begin{array}{l}\text { N2 RT- } \\
\text { PCR Ct }\end{array}$ & $\begin{array}{l}\text { RP RT- } \\
\text { PCR Ct }\end{array}$ & $\begin{array}{l}\text { Viral } \\
\text { Culture } \\
\text { PFU/ml }\end{array}$ & $\begin{array}{l}\text { N1 RT- } \\
\text { PCR Ct }\end{array}$ & $\begin{array}{l}\text { N2 RT- } \\
\text { PCR Ct }\end{array}$ & $\begin{array}{l}\text { RP RT- } \\
\text { PCR Ct }\end{array}$ & $\begin{array}{l}\text { N1 RT- } \\
\text { PCR Ct }\end{array}$ & $\begin{array}{l}\text { N2 RT- } \\
\text { PCR Ct }\end{array}$ & $\begin{array}{l}\text { RP RT- } \\
\text { PCR Ct }\end{array}$ & $\begin{array}{l}\text { N1 RT- } \\
\text { PCR Ct }\end{array}$ & $\begin{array}{l}\text { N2 RT- } \\
\text { PCR Ct }\end{array}$ & $\begin{array}{l}\text { RP RT- } \\
\text { PCR Ct }\end{array}$ \\
\hline 36 & 21.8 & 21.5 & - & & & & & & & & & & \\
\hline 148 & 26.1 & 25.4 & 32.9 & & 22.9 & 22.2 & 22.3 & & & & & & \\
\hline 149 & 19.2 & 18.0 & 24.0 & 41.7 & 29.4 & 29.8 & 21.8 & 30.0 & 31.6 & 36.6 & ND & ND & 36.0 \\
\hline 152 & 28.3 & 27.7 & 27.8 & 12.5 & 28.9 & 29.0 & 22.1 & 33.2 & 32.9 & 34.4 & & & \\
\hline 155 & 26.1 & 25.6 & 27.6 & & & & & & & & & & \\
\hline 156 & 26.2 & 26.1 & 28.2 & 1741.7 & 28.0 & 27.6 & 23.3 & 32.8 & ND & 33.7 & & & \\
\hline 157 & & & & & & & & & & & ND & ND & 26.9 \\
\hline 158 & 24.2 & 23.7 & 34.5 & 16666.7 & 30.0 & 30.8 & 23.0 & 32.4 & ND & 33.1 & ND & ND & 27.9 \\
\hline 159 & & & & & 22.1 & 21.2 & 23.5 & 31.7 & ND & 36.4 & ND & ND & 28.2 \\
\hline 160 & 23.2 & 22.7 & 27.0 & & & & & & & & ND & ND & 29.2 \\
\hline 162 & 23.1 & 22.7 & 28.7 & & & & & & & & ND & ND & 27.1 \\
\hline 163 & 22.5 & 22.1 & 28.3 & 533.3 & 27.1 & 27.2 & 22.1 & 32.7 & 33.9 & 34.5 & ND & ND & 30.6 \\
\hline 164 & 27.3 & 27.1 & 28.5 & 0.0 & & & & & & & & & \\
\hline 166 & 35.5 & 36.1 & 29.3 & 0.0 & & & & & & & & & \\
\hline 167 & 36.2 & 36.9 & 30.7 & & 28.0 & 27.9 & 23.1 & 34.1 & 41.1 & 31.5 & ND & ND & 30.1 \\
\hline 168 & 39.5 & 38.7 & 28.2 & 0.0 & & & & & & & & & \\
\hline 170 & 36.7 & 40.2 & 26.9 & 0.0 & 31.4 & 32.4 & 22.4 & 34.1 & 37.7 & 33.0 & ND & ND & 30.0 \\
\hline 171 & 39.4 & 41.0 & 30.9 & & & & & & & & & & \\
\hline 176 & 39.7 & ND & 28.0 & 0.0 & 33.9 & 36.9 & 22.3 & 35.0 & ND & 32.5 & ND & ND & 29.8 \\
\hline 177 & 33.3 & 33.7 & 26.2 & & & & & & & & & & \\
\hline 189 & & & & & & & & & & & ND & ND & 28.0 \\
\hline 202 & ND & ND & 33.7 & & & & & & & & ND & ND & 30.3 \\
\hline 210 & 39.8 & 44.3 & 29.1 & 0.0 & & & & & & & & & \\
\hline 217 & 35.9 & 37.1 & 24.4 & 0.0 & & & & & & & ND & ND & 28.1 \\
\hline 245 & & & & & & & & 34.5 & ND & 31.9 & ND & ND & 29.1 \\
\hline
\end{tabular}

\section{Supplementary Table 1: Serial patient samples from various tissues and secretions}

Catalogue of patient samples collected for research during the course of illness. N1, N2, and RP cycle threshold values are reported for each sample. WGS was performed on the bolded samples (accession numbers in table S2). Days of RDV treatment are denoted by grey shading and casirivimab/imdevimab was administered on day 163 (blue shading). Note that NP Ct values depicted in Figures 1,2 were obtained from clinical platforms and are not shown here.

Abbreviations: $\mathrm{ND}=$ Not Detected 


\begin{tabular}{lll}
\hline Sample Name & SRA Accession & GenBank Accession \\
\hline INP-0411-NP-148 & SRR16576689 & OL307721 \\
\hline INP-0411-NP-149 & SRR16576688 & OL307722 \\
\hline INP-0411-NP-152* & SRR16576677 & \\
\hline INP-0411-NP-155 & SRR16576668 & OL307723 \\
\hline INP-0411-NP-156 & SRR16576667 & OL307724 \\
\hline INP-0411-NP-158 & SRR16576666 & OL307725 \\
\hline INP-0411-NP-160 & SRR16576665 & OL307726 \\
\hline INP-0411-NP-162 & SRR16576664 & OL307727 \\
\hline INP-0411-NP-163 & SRR16576663 & OL307728 \\
\hline INP-0411-NP-164 & SRR16576662 & OL307729 \\
\hline INP-0411-NP-166 & SRR16576687 & OL307720 \\
\hline INP-0411-NP-177 & SRR16576686 & OL307730 \\
INP-0411-NP-36 & SRR16576685 & OL307731 \\
\hline INP-0411-SL-148 & SRR16576684 & OL307732 \\
INP-0411-SL-149 & SRR16576683 & OL307733 \\
\hline INP-0411-SL-152 & SRR16576682 & OL307734 \\
\hline INP-0411-SL-156 & SRR16576681 & OL307735 \\
\hline INP-0411-SL-158 & SRR16576680 & OL307736 \\
\hline INP-0411-SL-159 & SRR16576679 & OL307737 \\
\hline INP-0411-SL-163 & SRR16576678 & OL307738 \\
\hline INP-0411-SL-167 & SRR16576676 & OL307739 \\
\hline INP-0411-SL-170 & SRR16576675 & OL307740 \\
INP-0411-ST-149 & SRR16576674 & OL307741 \\
\hline INP-0411-ST-152 & SRR16576673 & OL307742 \\
INP-0411-ST-156 & SRR16576672 & OL307743 \\
\hline INP-0411-ST-158 & SRR16576671 & OL307744 \\
\hline INP-0411-ST-159 & SRR16576670 & OL307745 \\
INP-0411-ST-163 & SRR16576669 & OL307746 \\
\hline & & \\
\hline
\end{tabular}

*depth was sufficent to calculate allele frequency at position E802 in nsp12 but coverage was insufficent to generate consenus genome

\section{Supplemental Table 2: Accession numbers for submitted samples}


All Submitters of data may be contacted directly via www. gisaid.org

Authors are sorted alphabetically.

Accession ID

EPI_ISL_3354875

EPLISL_454642, EPI_ISL_454645
Originating
Laboratory CT-Dr. Katherine A.
Kelley State Public
Health Lab
Submitting Laboratory Centers for Disease Control and
evention Division of Viral Diseases.
Pathogen Discovery Pathogen Discovery

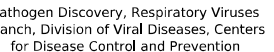

Authors

Vista Quen: Kristen Knipe; Kristine
Vivien Dugana; Yvette Unoarumhi

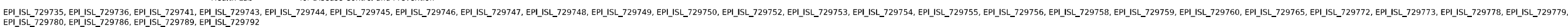

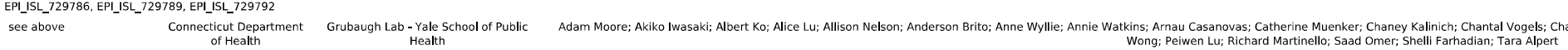

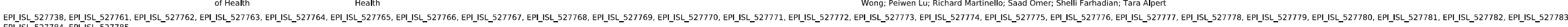
$\begin{gathered}\text { Connecticut State } \\ \text { Department of Public above }\end{gathered}$
Grubaugh Lab - Yale School of Public
Health

Albert Ko; Anderson Brito; Anthony Muyombwe; Chantal Vogels; Jafar Razeq; Ioseph Fauver; Mary Petrone; Nathan Grubaugh; Tara Alpert

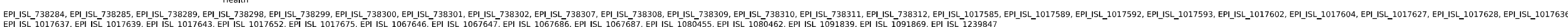
see above Connecticut Veterans' Grubaugh Lab - Yale School of Public
Affars Hospital Chantal Vogels; Danielle Plank; Ellen Foxman; Isabel ott; Joseph Fauver; Mary Petrone; Nathan Grubaugh; Shaili Gupta; Tara Alpert

EPI_ISL_802136

EPIIISL 430401 MSHS Clinical
Microbiology
Laboratories Laboratories

(1) Nru Langone Health Health
MSHS Pathogen Survellance Program

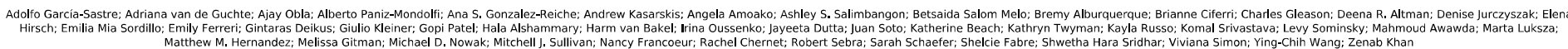

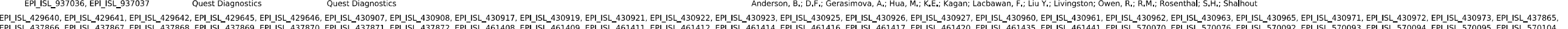

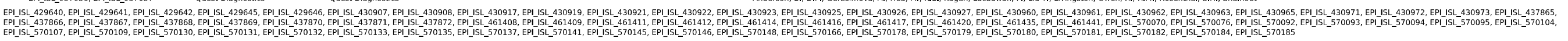 Un
University of W Wisconsin-
Keith Jerome; Keith R Jerome; Lasata Shrestha; Mei-Li Huang; Pavitra Roy
Gage Moreno; Katarina Braun; et al. AlDS Vaccine Research Laboratories

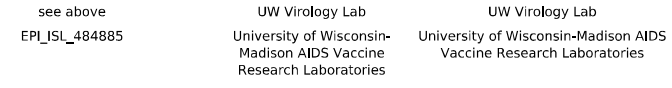

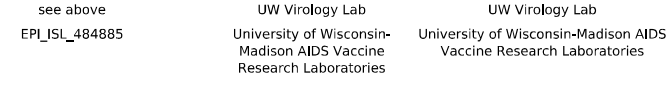

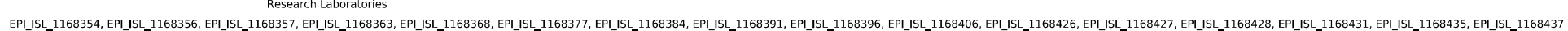

$$
\begin{gathered}
\text { Sa Connecticut above Grubaugh Lab - Yale School of Public } \\
\text { Health }
\end{gathered}
$$$$
\text { Chantal Vogels; Danielle Plank; Isabel ott; Oseseph Fauver; Mary Petrone; Nathan Grubaugh; Shaili Gupta; Tara Alpert }
$$

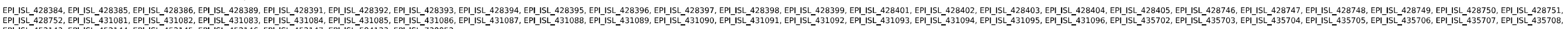

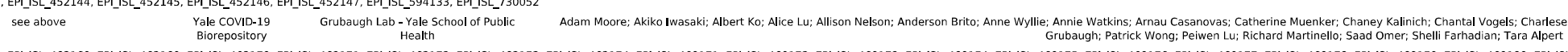

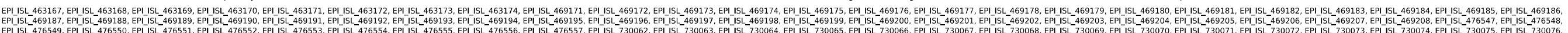

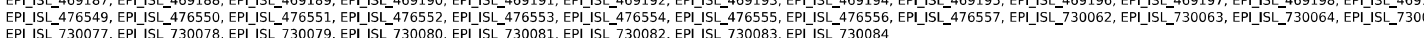

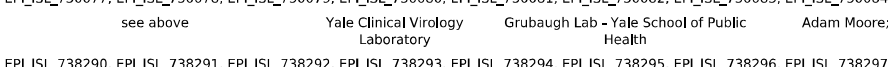
see above
Yale Pathology Lab Grubaugh Lab - Yale School of Public
Chantal Vogels; Danielle Plank; Ellen Foxman; Isabel Ott:; Joseph Fauver; Mary Petrone; Nathan Grubaugh; Shaili Gupta; Tara Alpert

\section{Supplemental Table 3: GISAID acknowledgments for local genomes used to generate Figure S1}


All Submitters of data may be contacted directly via www.gisaid.org

Authors are sorted alphabetically.

\begin{tabular}{|c|c|c|}
\hline $\begin{array}{l}\text { Accession ID } \\
\text { EPIIIL_4361721, } \\
\text { EPIISL_4362029 }\end{array}$ & $\begin{array}{l}\text { Originating Laboratory } \\
\text { Aegis Sciences Corporation }\end{array}$ & $\begin{array}{l}\text { Submitting Laborator } \\
\text { Centers for Disease } \\
\text { Control and Prevention } \\
\text { Division of Viral Iiseases } \\
\text { Pathogen Discovery }\end{array}$ \\
\hline EPI_ISL_2102156 & chuv & $\begin{array}{l}\text { Laboratory of genomics } \\
\text { and metagenomics }\end{array}$ \\
\hline $\begin{array}{l}\text { EPL_ISL_3473275 } \\
\text { EPL_ISL_2170967 }\end{array}$ & $\begin{array}{l}\text { CNR Virus des Infections Respiratoires - } \\
\text { France SSD } \\
\text { CS DE NIPOA }\end{array}$ & 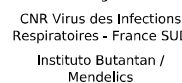 \\
\hline
\end{tabular}

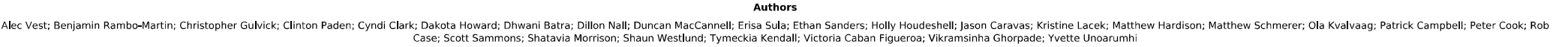

\section{Claire Bertelli; Damien Jacot; Gilbert Greub; Sébastien Aeby; Trestan Pillonel}

Antonin Bal; Bruno Lina; Gregory Destras; Gwendolyne Burfin; Hadrien Regue; Laurence Josset; Martine Valette; Quentin Semanas

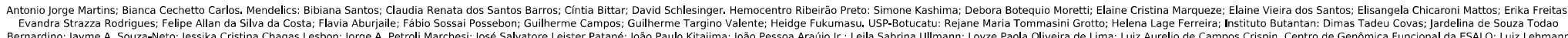

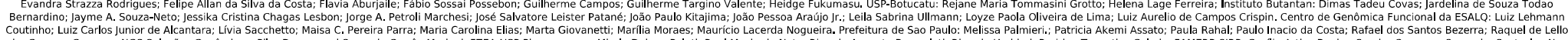

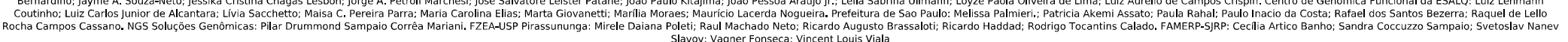

EPL_ILL_1138787 Centro Hospitalar do Baixo Vouga (CHBV) $\begin{aligned} & \text { Institute of Biomedicine } \\ & \text { (IBimED), Unviversidade de } \\ & \text { Aveiro }\end{aligned}$

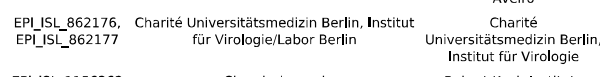

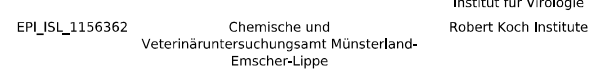

Gabriela Moura; Miguel Pinheiro and Manuel Santos; Patricia Arinto; Sofia Marques

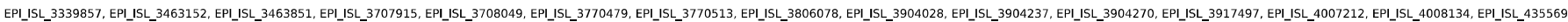

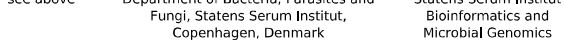

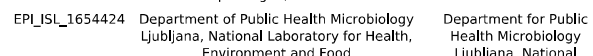

rosenc; Martin Bosili; Metka Paragi: Natasa Berginc; Tom Koritnik

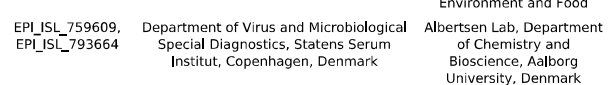

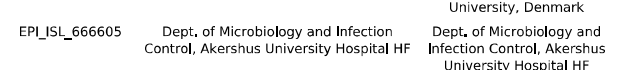

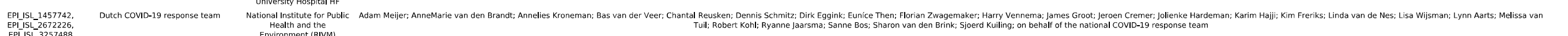
EPL_ISL_4636562 Genetica Molecular and Subdepartamento Instituto de Salud Publica
de Virologia ISP Chile chile EPLISL_2301853 $\begin{gathered}\text { Greek Genome Center, Biomedical } \\ \text { Research Foundation of then Academy of of } \\ \text { Athens (BRFA) }\end{gathered}$ Athens (BRFAA)
$\begin{gathered}\text { Foundation of the } \\ \text { Acadeny of Athens } \\ \text { (BRFA) }\end{gathered}$ $\begin{array}{ccc}\text { EPD_ISL_2187692 } & \text { MLAGYN - Laboratorio de Imunologia de } & \text { TLAGYN- Laboratorio de } \\ \text { Transplantes de Goias } & \text { Imunologia de } \\ \text { Transplantes de Goias }\end{array}$ EPDIISLL1581735, Helix/lllumina
EPIISL-1907121, Controrl and Prevention
Division of Vira Diseases,
Pathogen Discovery Pathogen Discovery
Houston Methodist
Hososital

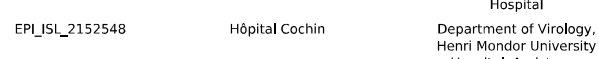
Henri Mondor University
Hospital, Assistance
Publique Hôpitaux de Publique Hópitaux de
Paris, nuiversití Paris--5st
Créteil, INSERM U955

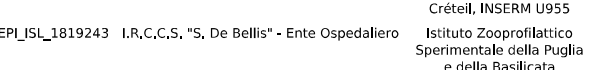
EPIIIL_L1678325,
EPI_IL__1678326

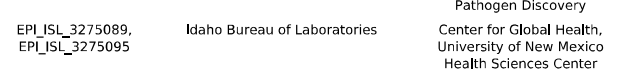

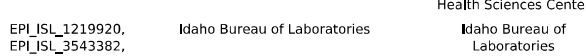
Andres Castillo; Barbara Parra; Constanza Campano; Gisselle Barra; Javier Tognarelli; Jorge Fernandez; Karen Orostica; Loredana Arrat; Patricia Bustos; Rodrigo Fasce; Soleddad Ulloa

Dimitrios Thanos; Emmanouil Athanasiadis; Giannis Vatsellas; Katerina Zoi; Theodoros Loupis

EPIIILL 3756841,
EPIISL 392280,
EPI_ISL-3923187

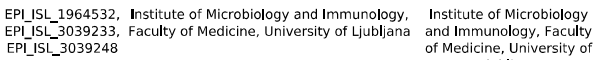

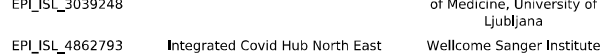

$\begin{gathered}\text { Wellcome Sanger Institute } \\ \text { for the CovI-19 } \\ \text { Genomics UK (COG-UK) }\end{gathered}$

EPI_ISL_1689555 Lab voor klinische biologie Lab voor klinische biologie

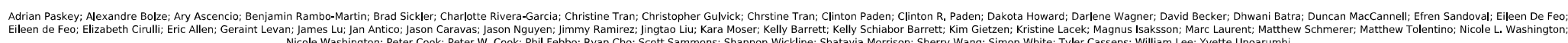
Ilya J. Finkelstein: James J. Davis; Jessica Cambric; Jimmy Gollihar; Kristina Reppond; Layne Pruitt; Madison N. Shyer; Marcus Nguyen; Matthew Ojeda Saavedra; Paul A. Christensen; Prasanti Yerramilli; Randall J. Olsen; Robert Olson; Ryan Gadd; S. Wesley Long; Sishir Subedi; and James M. Musser Alexandre Soulier; Christophe Rodriguez; Elisabeth Trawinski; Guillaume Gricourt; Jean-Michel Pawlotsky; Melissa N'Debi; Slim Fourati; Vanessa Demontant

Bianco A.; Capozzi L.; Del Sambro L.; Lippolis A,; Notarricola M.; Parisi A.; Simone D.

Alison Laufer Halpin; Ben L. Rambo-Martin; Clinton R. Paden; Dakota Howard; Darlene Wagner; Dave Wentworth; Dhwani Batra; Jasmine Padilla; Justin Lee; Katie Dillon; Krista Queen; Kristen Knipe; Kristine Lacek; Mark Burroughs; Matthew Schmerer; Mili Sheth; Peter Cook; Sam Shepard; Sarah Nobles; Shoshona Christopher Ball; Darrell Dinwiddie; Daryl Domman; Kurt Schwalm; Matthew Burns; Robert Voermans; Valerie Morley

"R. Beukelman; Aimee Ceniseros; Christian Loera; Christopher Ball'; Matthew Charles Burns; Robert L. Voermans

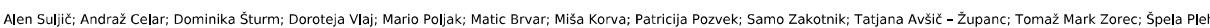


EPIISL_2044785, Laboratory Corporation of America
EPIIILL2927081 Nacional de Salud Publica.
Instituto Nacional de Salta

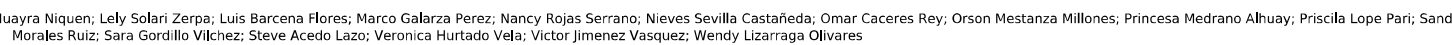
Peru.
Centers for Disease

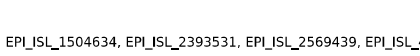
Control and Prevention,
Division of Viral Diseases,

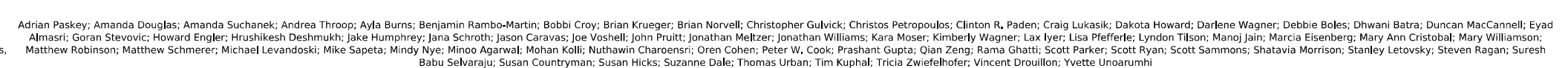

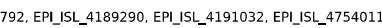

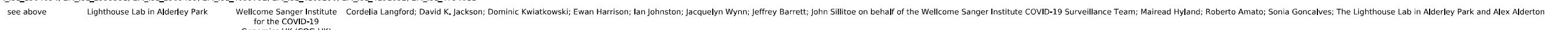

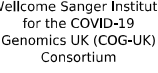

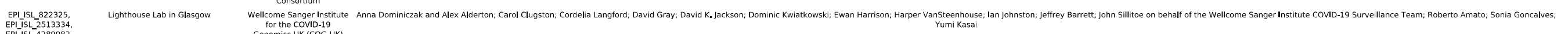

ERPIILL-2513334,
EPIIL-428992,
EPIISL-4683454,

EPIIIL-993421, Lighthouse Lab in Milton Keynes

EPIIIL-2236023,
EPIIIL-376330

EPI_ISL_1280209 Limbach - MVZ Labor Eveld \& Kollegen fort the coviD-19
Genomics UK (COG-UK)
Consortium

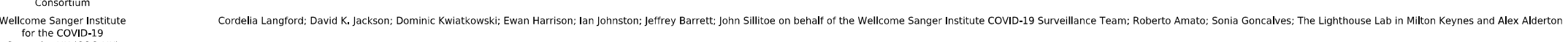

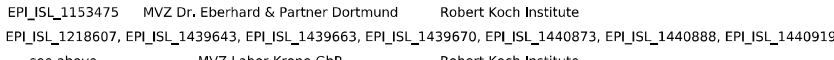

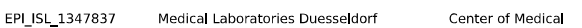

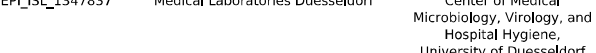

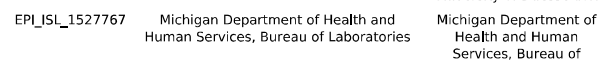
Health and Human
Services, Bureau of
Labobatories

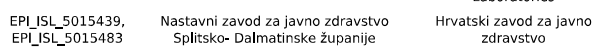

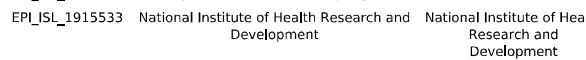

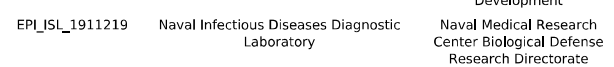

EP__IL__196461 New Mexico Department of Health $\begin{gathered}\text { Scientific Laboratory } \\ \text { New Mexico Department } \\ \text { of Heath scientific } \\ \text { Laboratory }\end{gathered}$

$\begin{array}{ccc}\text { EPL_IL_3903716 Nicolae Testemitanu State University of } & \begin{array}{l}\text { International Centre for } \\ \text { Medicine and Pharmacy }\end{array} \\ \text { Genetic Engineering and }\end{array}$ Biotechnology (ICGEB) and
ARG Oonen Lab latrorm
for Genome Sequencing

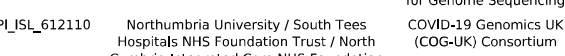

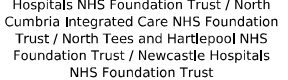

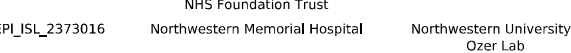

$\begin{array}{ccc}\text { EPL_ISL_5294882 Originating lab: Wales Specialist Virology } & \begin{array}{c}\text { Public Health Wales } \\ \text { Centre Sequencing lab: Pathogen }\end{array} \text { Microbiology Cardiff Walts }\end{array}$

EPI_LL__2037330 Pande

Pandemic Response Lab
R\&D

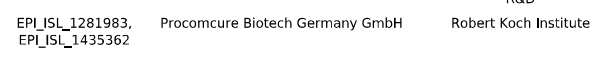

Rel__IL__253727 Randox Laboratories
forthe Sanger Institute
foviD-19

Genomics UK (IOOG-UK)
Consortium

EPLIILL5041500, Respiratory Virus Unit Microbiology
EPIISL_5281579

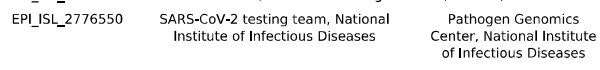

EPIIISL_2112492

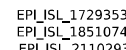

EPIIIL-2110293 SYNLAB Jena Oncoscreen

Robert Koch Institute
Robert Koch Institute

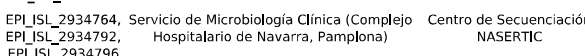

EPDISL_23832988 Servicio de Microbiología. Hospital General SegcoviD-SPAIN

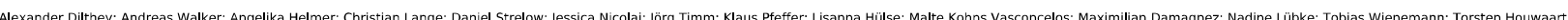

$$
\text { Blankenship HM; Riner D; Soehnlen MK }
$$

Irena Tabain; Ivana Ferencaak

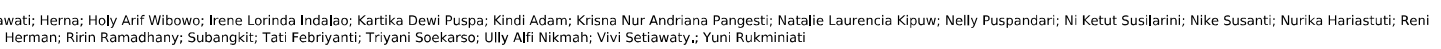

Andrea Luquette: Andrew Bennett; Bishwo Adhikari: Catherine Arnold; Francisco Malagon Bautista; Gregory Rice; Kimberly Bishop-Lilly; Kyle Long: Lindsay Glang: Logan Voegtly; Megan Schilling; Michael Deschenes; Regina Cer; Victor Sugiharto

Anastacia Griego-Fisher; D'eldra Malone; Ellie Johnson; Jennifer Benoit

Buzurnii L: Dal Monego S: Groppa S: Licastro D: Marcello A: Orsini E: Paraschiv A: Todiras M: Ulinici M Andrew Nelson; Brendan Payne; Clive Graham; Darren L Smith; Debra Padgett; Edward Barton; Emma Swindells; Garren Scott; Gary Black; Gary Eltringham; Giles S Holt; Greq R Young; Jane Greenaway; Jennifer Collins; John Allan; Joshua Loh: Lynn Dover; Matthew Bashton; Mohammad A Tariq; Paul Baker; Sarah
Essex; Steve Liggett; Wen C Yew; Yusri Taha

Chad J. Achenbach; Chao Qi: Egon A. Ozer; Judd F. Hultquist; Lacy M. Simons; Lawrence J J. Jennings; Michael G. Ison; Ramon Lorenzo-Redondo; Taylor J. Dean

Mec Birchley; Alexander Adams; Amy Gaskin; Angela Marchbank; Bree Gatica-Wilcox; Catherine Moore; Jason Coombes; Joanne Waatkins; Joel Southgate; Johnathan Evans; Laura Gifford; Lauren Gilbert; Lee Graham; Malorie Perry; Matthew Bull; Nicole Pacchiarini; Sally Corden; Sara Kumziene-Summerhayes; Sara Cybill del Castillo; Dylan Law; Haiping Hao; Henry Lee; Jon Laurent; Katharine Nelson; Melissa Hopkins; Michael Hammerling; Pradeep Bugga; Shinyoung Clair Kang; Sol Rey; William Ward

Cordelia Langford; David K. Jackson; Dominic Kwiatkowski; Ewan Harrison; lan Johnston; Jeffrey Barrett; John Sillitoe on behalf of the Wellcome Sanger Institute CoviD-19 Surveillance Team; Randox Laboratories and Alex Alderton; Roberto Amato; Sonia Goncalves

PHE Covid Sequencing Team

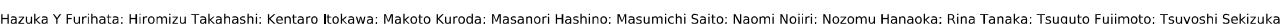

Ana Miqueleiz; Ana Navascués; Carmen Ezpeleta Baquedano

María Dolores Tirado Balaguer and SeacoVID-SPAIN consortium; Rosario Moreno Muños 


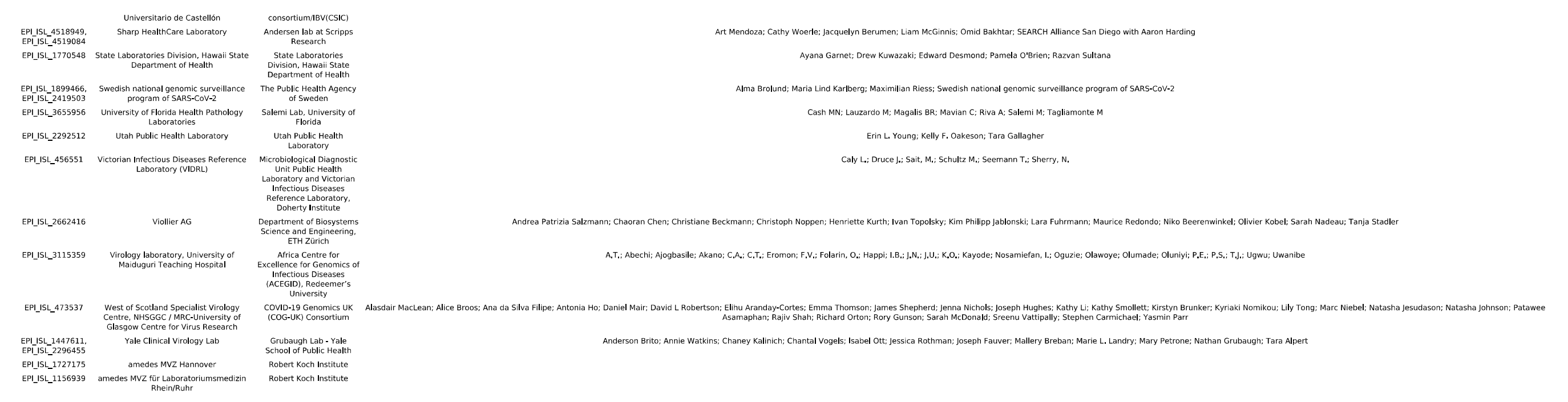

Supplemental Table 4: GISAID acknowledgments for genomes containing nsp12 E802D used to generate Figure S3 